\title{
A New Conceptual Framework for Integrating Earth Observation in Large-scale Wetland Management in East Africa
}

\author{
Stefanie Steinbach ${ }^{1,2,3}$ (D) Natalie Cornish ${ }^{4}$ - Jonas Franke ${ }^{4} \cdot$ Konrad Hentze $^{2}$ (D) Adrian Strauch $^{5}$ (D) \\ Frank Thonfeld $^{6,7}$ (D) Sander J. Zwart ${ }^{8}$ (D) Andrew Nelson $^{1}$ (i)
}

Received: 21 December 2020 / Accepted: 27 May 2021 / Published online: 4 October 2021

(C) The Author(s) 2021

\begin{abstract}
Wetlands are abundant across the African continent and provide a range of ecosystem services on different scales but are threatened by overuse and degradation. It is essential that national governments enable and ensure the sustainable use of wetland resources to maintain these services in the long run. As informed management decisions require reliable, up-to-date, and large coverage spatial data, we propose a modular Earth observation-based framework for the geo-localisation and characterization of wetlands in East Africa. In this study, we identify four major challenges in spatial data supported wetland management and present a framework to address them. We then apply the framework comprising Wetland Delineation, Surface Water Occurrence, Land Use/Land Cover classification and Wetland Use Intensity for the whole of Rwanda and evaluate the ability of these layers to meet the identified challenges. The layers' spatial and temporal characteristics make them combinable and the information content, of each layer alone as well as in combination, renders them useful for different wetland management contexts.
\end{abstract}

Keywords Wetland delineation $\cdot$ Wetland characterization $\cdot$ Copernicus $\cdot$ Rwanda $\cdot$ Food security $\cdot$ Environmental protection

\section{Introduction}

African wetland landscapes provide a range of ecosystem services, such as water provision, food provision, and climate regulation (Langan et al. 2018). Besides water purification, flood attenuation, carbon storage and sequestration, and the provision of fodder, fibre, and fuel wood, they provide unique and highly productive landscapes. These landscapes have
Stefanie Steinbach

s.steinbach@utwente.nl; stefanie.steinbach@ruhr-uni-bochum.de

Natalie Cornish

nataliercornish@gmail.com

Jonas Franke

franke@rssgmbh.de

Konrad Hentze

k.hentze@geographie.uni-bonn.de

Adrian Strauch

astrauch@uni-bonn.de

Frank Thonfeld

frank.thonfeld@dlr.de

Sander J. Zwart

s.zwart@cgiar.org

Andrew Nelson

a.nelson@utwente.nl
1 Faculty of Geo-Information Science and Earth Observation (ITC), University of Twente, P.O. Box 217, 7500

AE Enschede, The Netherlands

2 Remote Sensing Research Group (RSRG), University of Bonn, Meckenheimer Allee 166, 53115 Bonn, Germany

3 Department of Geography, Ruhr-University Bochum, Universitätsstraße 150, 44801 Bochum, Germany

4 Remote Sensing Solutions GmbH (RSS), Dingolfinger Straße 9, 81673 München, Germany

5 Center for Remote Sensing of Land Surfaces (ZFL), University of Bonn, Genscherallee 3, 53113 Bonn, Germany

6 German Remote Sensing Data Center (DFD), German Aerospace Center (DLR), Münchener Straße 20, 82234 Weßling, Germany

7 Department of Remote Sensing, University of Würzburg, Oswald-Külpe-Weg 86, 97074 Würzburg, Germany

8 International Water Management Institute (IWMI), PMB CT 112, Cantonments, Accra, Ghana 
great ecological value, and are recognized as biodiversity hotspots of global importance, often harbouring endemic flora and fauna (Keddy et al. 2009; Junk et al. 2013). Wetlands often have greater water availability and more fertile soils than adjacent traditionally farmed and degraded uplands. Therefore, their agricultural potential is considerable and can support agricultural development in sub-Saharan Africa (SSA) (Dixon and Wood 2003; Rebelo et al. 2009; Rodenburg et al. 2014). Food security strategies in SSA have targeted wetlands for further cropland expansion and agricultural intensification to reach self-sufficiency. Lowland rice agriculture in particular is strongly promoted in wetlands with the hope to reduce dependency on food imports, boost food security and alleviate poverty (Demont 2013). A dual strategy of use and protection is needed to conserve ecosystem integrity (van Oort et al. 2015; van Ittersum et al. 2016). Inappropriate agricultural use is a major threat to wetlands and, among other impacts, has already caused tremendous losses of wetland area in Africa (Chapman et al. 2001; Junk et al. 2013; Mitchell 2013; Darrah et al. 2019). This is particularly detrimental to livelihoods in SSA, where local populations often directly depend on wetland ecosystem services (Nabahungu and Visser 2011; Namaalwa et al. 2013).

Due to the range of ecosystem services wetlands provide at different scales, their use is a cross-cutting issue. They are targeted by national policies as well as by regionally concerted strategies like the National Rice Development Strategies (NRDS) established through the Coalition for African Rice Development (CARD), which aimed at doubling rice production in SSA between 2008 and 2018 (Demont 2013). Also, wetland landscapes are increasingly part of national to global protection efforts. Among those, Multilateral Environmental Agreements (MEAs) like the Convention on Biological Diversity (CBD) with its associated Aichi targets (Petrou et al. 2015), and the Ramsar Convention on Wetlands towards their sustainable use are making an important contribution to wetland conservation worldwide (Finlayson et al. 2011).

There is no simple remedy to achieve sustainable wetland management with increased food security and environmental protection at the same time, but there is consensus that the first step towards informed policy making and planning for wetland landscapes requires quantified information on wetland location, state, and dynamics through detailed inventorying, as well as the possibility to repeat those analyses over time to track changes (Ozesmi and Bauer 2002; Rodenburg et al. 2014; Perennou et al. 2018). However, there are still major data limitations affecting the informed management and planning of wetlands in Africa. Remote sensing data have the potential to contribute to this information requirement by providing detailed and frequent spatial information that is consistent across administrative boundaries and can thus support management, policy making, and policy implementation (Merot et al. 2006; MacKay et al. 2009; Rebelo et al. 2009; Amler et al. 2015; Leemhuis et al. 2017; Perennou et al. 2018). In the following, we list four of the most common problems of wetland management in East Africa which are related to spatial information.

\section{Lack of Spatially Explicit Information}

Detecting the location and size of wetlands are prerequisites for planning interventions, both for agricultural development and for conservation measures (Rodenburg et al. 2014), but spatially explicit data on wetlands is often lacking or inadequate, particularly in Africa (Davidson 2014; Amler et al. 2015). Earth observation (EO) can play a vital role in closing this data gap (MacKay et al. 2009). However, the lack of comprehensive datasets can be understood as the result of the various challenges that wetland detection poses. Wetlands usually do not have crisp boundaries, but are located in the transition zone between terrestrial and aquatic ecosystems (Dronova 2015). Also, wetlands of the same type may show large spectral, temporal, and spatial differences in reflectance or backscatter values, whereas the same land cover within and outside wetlands may even have similar values, which makes them difficult to detect and classify (Mahdavi et al. 2018). Although satellite imagery and aerial photography from coarse to very fine spatial resolutions are used in wetland research (Guo et al. 2017; Perennou et al. 2018; Mahdavi et al. 2018), existing large-scale EO-based datasets are of limited suitability for use in wetland landscapes, both regarding their delineation and their characterization. For instance, the Copernicus Global Land Service Land Cover product (Buchhorn et al. 2020) contains one class herbaceous wetlands, but the spatial resolution of $100 \mathrm{~m}$ fails to account for narrow wetland features. A high level of spatial detail is required to adequately map wetland landscapes and particularly their seasonally flooded areas (Rebelo et al. 2011). In addition, such global products are not focussed on wetland ecosystems and hence are not suited to adequately characterize different wetland types. We therefore classify the availability of up-to-date, large-coverage and high spatial resolution data on wetland location and extent as an issue and requirement for wetland mapping at the national scale.

\section{Representation of Spatio-temporal Variability}

Also regional products with higher spatial resolution, such as the $30 \mathrm{~m}$ resolution Landsat based Africover (FAO 2013) or the more recent $20 \mathrm{~m}$ resolution Sentinel-2 based S2 Prototype Land Cover Map of Africa 2016 (Lesiv et al. 2017) alone do not suffice to provide more detailed information about, for example, land use characteristics and flooding regimes, which 
are essential for agricultural development and ecosystem monitoring. Additionally, wetlands are not only subjected to medium- and long-term variability caused by climatic fluctuations and land use, but are highly dynamic landscapes characterized by inter-seasonal change in inundation and vegetation in response to the hydrological cycle (Guo et al. 2017; Perennou et al. 2018; Mahdavi et al. 2018). Water presence is the core element of wetlands and the reason for their floral and faunal composition, as well as a central contributing factor to their agricultural use potential. Therefore, both the presence and the variability of water need to be reflected in wetland related mapping (Perennou et al. 2018). In recent years, several large-scale surface water datasets that cover Africa have been developed. Among these is the Global Inundation Extent from Multi-Satellites - Downscaled 15 arcseconds (GIEMSD15). The global inundation map was created by downscaling coarse-resolution EO based data to a spatial resolution of $500 \mathrm{~m}$, including mean annual minimum, mean annual maximum and long-term maximum inundation (Fluet-Chouinard et al. 2015). The Global WaterPack provides daily information on global inland water bodies derived from Moderate Resolution Imaging Spectroradiometer (MODIS) data at $250 \mathrm{~m}$ spatial resolution (Klein et al. 2017). The Joint Research Centre's (JRC) Global Surface Water product (Pekel et al. 2016) provides information about long-term surface water changes and to some extent about surface water seasonality at $30 \mathrm{~m}$ resolution from Landsat data, recently additionally incorporating Sentinel-2 imagery. Such high spatial resolution data is necessary to characterize water dynamics in the often narrow wetland landscapes, but optical data is problematic in the tropics where high air moisture and frequent and extensive cloud cover interfere with image acquisition (Dronova et al. 2015). The second issue identified is therefore the robust representation of spatio-temporal wetland variability, with an emphasis on water cycle-related land cover, making use of multi-temporal data at adequately high spatial and temporal resolution.

\section{Comparability of Data and Repeatability of Approaches}

Many African countries have national wetland datasets. The Rwanda Environment Management Authority (REMA), for example, published a national wetland dataset which was manually digitized from Landsat and ASTER imagery in 2008 (REMA 2008). However, the dataset has not been updated since, with manual digitization as a central step in its creation being one potential reason for this lack of update, as it is a time consuming and partly subjective process. Amler et al. (2015) found that available wetland datasets for Kenya, Tanzania, Uganda, and Rwanda are inconsistent. Therefore, recommendations for future work on wetlands include introducing a higher degree of automation and shared nomenclature to enhance comparability between datasets of the same area, as well as between different areas (Leemhuis et al. 2017; Perennou et al. 2018; Mahdavi et al. 2018). Regional and topical initiatives such as GlobWetland Africa, GEOWetlands, and the Satellite-based Wetland Observation Service (SWOS) have laid the foundation towards harmonized approaches (Strauch et al. 2016; Weise et al. 2020). To assess trends over time and make mapping results comparable across African wetland landscapes, the third identified issue is therefore the need for consistent, comparable, and repeatable mapping approaches.

\section{Lack of Quantified Information on Drivers of Wetland Change}

In global comparison, natural wetland loss occurred at high rates in Africa throughout the 20th and 21st centuries (Davidson 2014). Natural wetland area in SSA declined by an estimated $42 \%$ between 1970 and 2014, whereas globally $35 \%$ of the natural wetland area was lost in the same period (Darrah et al. 2019). Land conversion, particularly to agriculture, and overuse are among the main proximate causes for wetland degradation and loss (MEA 2005; Junk et al. 2013; Asselen et al. 2013). Although the quality of interlinkages between pressure through land use and wetland ecosystem integrity are largely known, the quantification of drivers of change in a spatially explicit way is barely addressed, particularly for African wetland landscapes. A land-cover based method for the quantified rapid assessment of anthropogenic disturbances of wetlands was developed in South Africa by Kotze et al. (2012) and adapted for East Africa whilst integrating satellite imagery by Beuel et al. (2016). However, consistent large-coverage methods to assess land cover and use intensity as indicators for modelling ecosystem change still have to be developed (Erb et al. 2013; Beuel et al. 2016). The need for quantified data on drivers of change is thus the fourth issue we identify.

The objective of this study is to address the need for accurate spatial data for informed national wetland management in Africa by proposing a layered, remote sensingbased information framework for wetland characterization. First, we address the above challenges by presenting the respective spatial data layers and methodologies to generate them using satellite data from the European Space Agency's (ESA) Copernicus Programme. Then, we apply our framework in a case study on wetlands management in Rwanda. Finally, we discuss the use of the generated data and the applicability of the framework in the context of wetland management in East Africa, accounting for the capacity of the approach to support wetland management in African countries. 


\section{Materials and Methods}

\section{Study Site}

Rwanda is a landlocked country in the Great Lakes Region of Africa and is located between $1^{\circ} 4^{\prime}$ and $2^{\circ} 51^{\prime} \mathrm{S}$ and $28^{\circ} 53^{\prime}$ and $30^{\circ} 53^{\prime}$ ' E. It measures $26,338 \mathrm{~km}^{2}$ and borders Uganda to the north, Tanzania to the east, Burundi to the south and the Democratic Republic of the Congo to the west. It is located at the divide of the Congo and Nile basins (REMA 2008) and can be sub-divided into 10 distinct agro-climatic zones (ICRAF 2015), as shown in Fig. 1. The long rainy season spans from March to May, whereas the short rainy season starts in September and ends in November (Muhire and Ahmed 2015). Mean annual rainfall is $1160 \mathrm{~mm}$ and the tropical climate is attenuated to an average temperature of $18.8^{\circ} \mathrm{C}$ (Fick and Hijmans 2017) by the relatively high altitudes of $900 \mathrm{~m}$ in the east and up to $4,500 \mathrm{~m}$ in the mountainous Albertine Rift region in the west. Wetlands in Rwanda can be classified into three major categories (Cambrezy 1981):

- large wetland complexes characterized by low relief and low drainage, and partly by the occurrence of lakes through damming, e.g., the Akagera wetland complex including Akanyaru and Akagera, Nyabugogo, and Lake Muhazi;

- discontinuous wetlands of differing size found in valley bottoms, where they formed in areas of accentuated relief due to anomalies like trench formation, local subsidence, or lava flows, e.g., Bugarama, Kamiranzovu, Rugezi, Buberuka, and some wetlands in the southwestern part of Rwanda;

- small, seasonally inundated valley bottom wetlands that are associated with adjacent hills, are spatially continuous, but have less pronounced wetland characteristics; as found in the Cyangugu region at the foot of Nyungwe.

\section{Current Wetland Management in Rwanda}

According to REMA's wetland delineation dataset from 2008, approximately $10.6 \%$ of the country is covered by wetlands, with $41 \%$ of this wetland area being covered with natural vegetation, $53 \%$ being under cultivation and $6 \%$ being fallow (REMA 2008). $13.5 \%$ of the wetland landscapes are at least partially enclosed within national parks or reserves, and $14.4 \%$ constitute source wetlands or wetlands acting as dams, which are under special protection (REMA 2008). The delineation forms a baseline wetland inventory but has not been updated since. Also, the dataset is a static binary one not accounting for interseasonal or interannual fluctuations related to the water cycle. Overuse was identified as a main driver of wetland degradation (REMA 2009), but quantitative information on potential hotspots of wetland degradation and loss is missing. A range of laws, policies, and agreements relate to wetland use and protection. Yet, without a consistent, comprehensive, and up-to-date database of wetland location and state, both food production in wetland landscapes and their protection remain a challenge. For national wetland management and monitoring wetland status, assessments need to be conducted on a regular basis and be comparable across country boundaries for effective reporting towards international conventions.

Rwanda's reliance on wetlands for food security can be explained by the country's high population density, estimated at 491 inhabitants $/ \mathrm{km}^{2}$ in 2020 , making Rwanda one of the most densely populated African countries (UN DESA 2019). The food security level of Rwanda according to the Global Hunger Index (GHI) is still serious, although the score reduced by $43.1 \%$ since 2000 (von Grebmer et al. 2020). Therefore, in addition to their historically increasing use over time (Meschy 1989), wetlands have become an integral part of policies for increasing agricultural production in order to sustain and improve food security, as well as serve the export market. Rwanda's Irrigation Master Plan identifies by far the highest irrigation potential in wetlands as compared to runoff, direct river and flood water, and other water sources, with a prospect of almost doubling rice yields and more than tripling sugarcane yields under optimal irrigation (Malesu et al. 2010). Accordingly, Rwanda's (NRDS) for 2010-2018 aimed to raise rice production through expansion into wetlands and by increasing productivity levels from 5.8 to $7.0 \mathrm{t} / \mathrm{ha}$, for example through the installation of irrigation structures in wetlands which are already under cultivation (MINAGRI 2011).

Wetland use and protection are organized by a number of institutions, laws, and strategies. The Rwandan central government plays the most important role in wetland management to balance increased agricultural production and wetland protection. Although decentralized wetland management entities are stipulated by the Organic Law on the Environment 2005, these entities are undefined and wetland related activities must be approved by the Prime Minister with the following institutions involved in their management (Heermans and Ikirezi 2015): the Ministry of Natural Resources (MINIRENA), the Rwanda Natural Resources Authority (RNRA), the Rwanda Environmental Management Authority (REMA), and the Ministry of Agriculture and Animal Resources (MINAGRI). MINIRENA is the ministry in charge of legislation regarding land use and the environment and is the superior institution concerning wetland management. Its sub-agencies RNRA and REMA are responsible for the management of water, forests, 


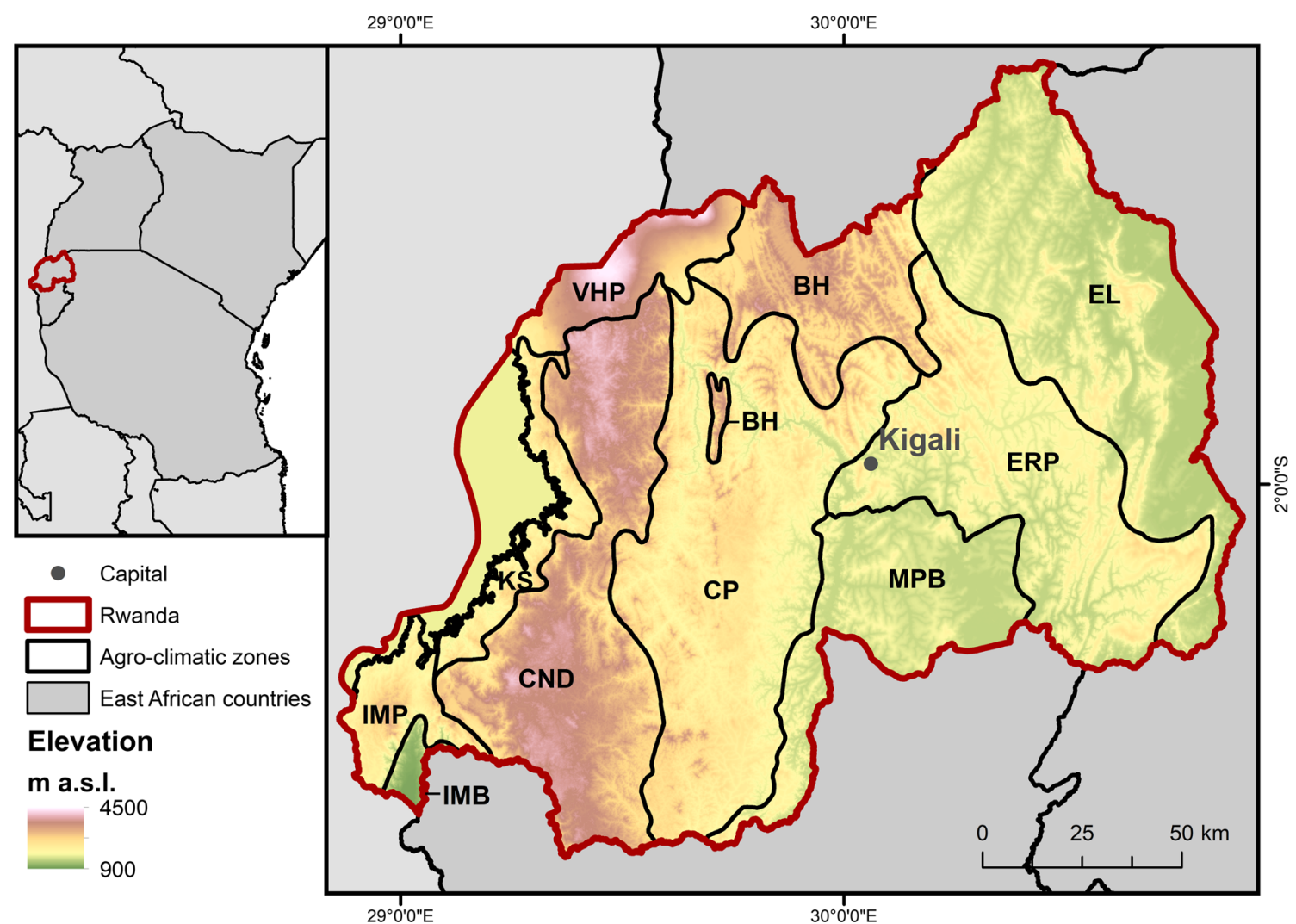

Fig. 1 Topography of Rwanda and agro-climatic zones (ICRAF 2015): $\mathrm{BH}=$ Buberuka Highlands, $\mathrm{CND}=$ Congo Nile Watershed Divide, $\mathrm{CP}=$ Central Plateau, EL $=$ Eastern Lowland, ERP $=$ Eastern Ridge and

and mineral resources, and the implementation of environmental regulations, respectively. REMA also approves all Environmental Impact Assessments (EIA) that precede wetland use. MINAGRI is less explicitly involved in wetland governance itself, but MINIRENA and MINAGRI coordinate concerning larger wetland development projects for agriculture (Heermans and Ikirezi 2015). The named institutions implement national legislation like the Organic Law on Land 2005, which was replaced by the Land Law 2013, defining protected wetlands as public state domain and unprotected wetlands as private state domain with the possibility of leasehold. The Organic Law on the Environment contains environmental protection policies, including wetland protection measures. These, for example, prohibit: waste disposal in wetlands; their burning; development within a buffer zone of $20 \mathrm{~m}$ around wetlands; and wetland use without an EIA. The Land Policy 2005 and the Environmental Policy 2004 similarly stress the need for careful and sustainable management of wetlands, with the latter emphasizing the need for wetland inventorying towards their good management under state domain (Heermans and Ikirezi 2015). Rwanda's Nationally Determined Contribution to the Paris Agreement includes wetland restoration as a means to ensure water security (GoR 2020). Apart from national laws and policies, Rwanda is involved in several wetland relevant international
Plateau, $\mathrm{IMB}=\mathrm{Imbo}, \mathrm{IMP}=$ Impala, $\mathrm{KS}=\mathrm{Kivu}$ Lake Shore, $\mathrm{MPB}=$ Mayaga Plateau \& Central Bugesera, VHP = Virunga Summit and High Plains

agreements. Among these are the MEAs Ramsar Convention and the CBD, as well as the United Nations Sustainable Development Goals (SDGs).

Rwanda has the ambitious aim to develop a national and mostly centralized approach to wetland management. The importance of wetlands as a resource along with the subsequent need for more sustainable use is clearly identified, as is the need for a respective nation-wide wetland inventory and classification (REMA 2009).

\section{Framework for Multi-layer Characterization of Wetlands}

Our approach can be seen as an extension of the valley bottom wetland categorization for wetland management by Merot et al. (2006), who classify wetland definition into three levels: potential, existing, and efficient wetlands (PEEW approach). The potential for wetland occurrence depends on enabling factors such as topography and climate, whereas the existence of wetlands is linked to actual land cover and hydrological conditions. The efficient wetland category describes ecosystem properties (Merot et al. 2006). In wetland monitoring and management, this categorization can deliver information on wetland loss and on changes in wetland functional categories and was adopted in a remote sensing based study of wetlands 
in north-eastern France (Rapinel et al. 2019). Accordingly, the basis of our wetland characterization framework consists of a potential wetlands map (potential wetlands), from which actual wetland boundaries are derived (existing wetlands). In the next step, they are described in terms of land cover, flooding frequency, and use intensity (efficient wetlands). Each layer is evaluated using qualitative and quantitative methods according to its temporal extent and reference data availability, and the results for Rwanda are presented. We employ the Ramsar definition for inland wetlands, which includes "areas of marsh, fen, peatland or water, whether natural or artificial, permanent or temporary, with water that is static or flowing, fresh, brackish or salt" (Matthews 2013, p. 38). This broad definition allows us to include all types of water-based ecosystems that occur across Rwanda. Our emphasis lies on the conceptualization of a wetland delineation and characterization framework based on the coherence of the datasets at scales beyond case studies. It is supposed to allow for a comprehensive national wetland assessment and provide Rwandan institutions with solutions to their manifold spatial data needs, with the option to extend these analyses beyond country boundaries. The framework's potential use for wetland management will be evaluated against these information needs.

The major EO data sources are the Sentinel-1 and Sentinel2 satellites from the European Copernicus Programme. Their spatial resolutions are $20 \mathrm{~m}$ for the Sentinel-1 Ground Range Detected (GRD) product in Interferometric Wide swath (IW) mode and 10 to $60 \mathrm{~m}$ for Sentinel-2 imagery. Both satellite constellations consist of A- and B-units, with a revisit time of 5 days at the equator for Sentinel-2 (Berger et al. 2012; Drusch et al. 2012) and 12 days in ascending or descending mode (or 6 days for both) for Sentinel-1 (ESA 2019). These high spatial and temporal resolutions make them suitable for the creation of data products to capture the temporal dynamics and spatial variation of wetland landscapes. The data are available free of charge, which is also true for the additional data we used, the Digital Elevation Model (DEM) of the Shuttle Radar Topography Mission (SRTM) (Lehner et al. 2008) and highresolution remote sensing imagery from Google Earth. Commercial RapidEye satellite imagery at $5 \mathrm{~m}$ spatial resolution was used for validation purposes (RapidEye AG 2007). Four data products were created: (1) a Wetland Delineation, (2) Surface Water Occurrence (SWO), (3) a Land Use/Land Cover classification (LULC), and (4) Wetland Use Intensity (WUI) (Fig. 2).

\section{Wetland Delineation}

To tackle the challenges described in Introduction, an approach to delineation is required that is robust against confusion between similar land covers in upland and lowland areas,

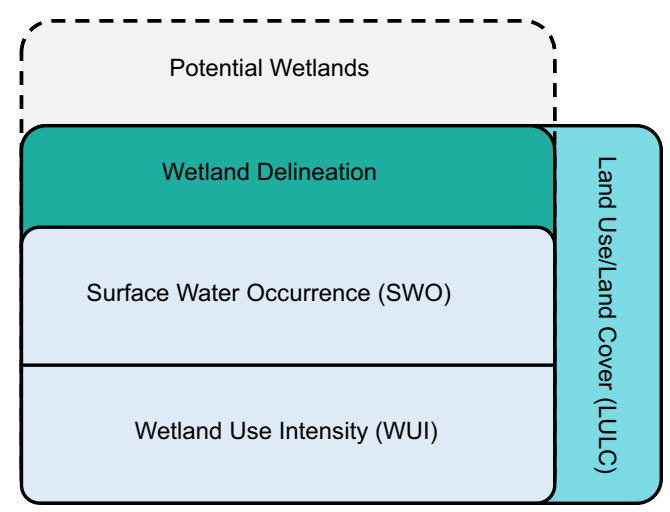

Fig. 2 Scheme for modular wetland characterization including Potential Wetlands, (1) Wetland Delineation, (2) Surface Water Occurrence (SWO), (3) Wetland Use Intensity (WUI) and (4) Land Use/Land Cover (LULC) classification

while providing spatial detail and information on wetland size and location. Therefore, our delineation approach depicted in Fig. 3 consists of two stages, first defining the potential wetland area based on topographic indices following the approach described for wetland delineation in Albania by Weise et al. (2020), and then delineating actual wetlands with additional optical satellite data. Thus, confusion due to similar spectral signals inside and outside wetlands is reduced. The potential wetland map is based on the combination of topographic indices derived from the SRTM DEM. The result shows probabilities (values from 0 to 1 ) to find wetland ecosystems according to topographic and hydrological criteria.

Three global DEMs of high spatial resolution were considered for the creation of the Potential Wetlands layer: The SRTM 1 Arc-Second Global DEM, the Advanced Spaceborne Thermal Emission and Reflection Radiometer Global DEM Version 2 (ASTER GDEMV2), and the TerraSAR-X-Add-on for Digital Elevation Measurements DEM (TanDEM-X DEM). The Shuttle Radar Topography Mission was flown in 2000 and acquired data in C-band Synthetic Aperture Radar (SAR) to produce a near-global DEM with an absolute vertical accuracy of under $9 \mathrm{~m}$. The greatest errors occur in steep terrain and above smooth sandy surfaces (Farr et al. 2007). In 2014, the SRTM DEM was released globally at approximately $30 \mathrm{~m}$ spatial resolution at the Equator (JPL 2014) and is available free of charge. Likewise, the ASTER GDEMV2 is free and has a spatial resolution of approximately $30 \mathrm{~m}$. The ASTER GDEM Version 1 is based on the ASTER optical stereo image archive from 2000 to 2008 (Urai et al. 2012). For Version 2, released in 2011, an increased number of input images and an improved algorithm were applied. However, the resulting vertical accuracy of $17 \mathrm{~m}$ (Tachikawa et al. 2011) is lower than that of the SRTM DEM. Also, several local comparative studies suggest that there has been an improvement between versions, but that the ASTER GDEMV2 quality and accuracy remain below those of the different SRTM DEM versions 
(Suwandana et al. 2012; Athmania and Achour 2014; Grohmann 2018; Carrera-Hernández 2021). From 2010 to 2015, the TanDEM-X mission delivered elevation data from $\mathrm{X}$-band single-pass radar interferometry towards a consistent global DEM at $12 \mathrm{~m}$ spatial resolution (Krieger et al. 2007; Martone et al. 2012; Rizzoli et al. 2017). Its vertical accuracy requirement of under $2 \mathrm{~m}$ for flat and under $4 \mathrm{~m}$ for steep terrain is largely met and thus outperforms the SRTM DEM (Rizzoli et al. 2017; Wessel et al. 2018). However, its commercial distribution by the public private partnership of the German Aerospace Center (DLR) and Airbus Space and Defence may, as outlined by Grohmann (2018), hamper its wider adoption. Additionally, areas classified as sensitive, like the border between Rwanda and the Democratic Republic of the Congo, may lead to delayed availability or unavailability of DEM tiles. For the objective of developing coherent and adoptable methods towards wetland mapping, we therefore valued the accessibility and availability of the SRTM DEM, substantiated with a large body of literature successfully using it for large-scale wetland mapping (e.g. Bwangoy et al. 2010; Ndayisaba et al. 2017; Ludwig et al. 2019) over the higher performance of the TanDEM-X DEM.

The methodology by Weise et al. (2020) was adjusted to the landscape characteristics of Rwanda to produce a potential wetland map with a spatial resolution of $30 \mathrm{~m}$. The Topographic Wetness Index (TWI) (Beven and Kirkby 1979; Böhner and Selige 2006), the Multi-resolution Index of Valley Bottom Flatness (MrVBF) (Gallant and Dowling 2003), and a floodplain index (FPI) were derived from the SRTM DEM. The TWI is based on the slope and the specific catchment area (Beven and Kirkby 1979; Böhner and Selige 2006) and the MrVBF defines and distinguishes valley bottoms from hill slopes (Gallant and Dowling 2003). Both indices were calculated using the GIS software System for Automated Geoscience Analyses (SAGA). For the FPI, floodplains were derived by combining the slope with the river stream network and applying a cost distance calculation. Cost distance was rescaled to values between 0 and 1 (high to low cost distance). TWI, MrVBF and FPI were combined with the weights 1-2-1 to reflect the probability to find wetland habitats.

The delineation of actual wetlands follows the proposition of defining wetlands relative to their surroundings instead of in absolute terms (Semeniuk and Semeniuk 1995). Objectbased image analysis (OBIA) was already successfully applied by Fitoka et al. (2020) in the context of large-scale classification of wetlands in Greece, using the potential to distinguish between wetlands and uplands with contextual information. We developed a methodology that conducts an automated, object-based pre-classification in eCognition, followed by manual post-classification of false-positives and falsenegatives against RapidEye images taken in 2017. In the first step, the single most cloud-free Sentinel-2 image of 2017 per tile (in total 7 images) was selected and cloud-masked. Also, a time series of all available Sentinel-2 scenes in 2017 with less than $20 \%$ cloud cover were cloud masked and used to calculate the mean Normalized Difference Water Index (NDWI) (Gao 1996) and the mean Normalized Difference Vegetation Index (NDVI) (Tucker 1979) per pixel for 2017 across the study area. The Potential Wetlands layer, mean NDWI, mean NDVI, and Sentinel-2 mosaic were stacked and segmented into objects. These objects were created using homogeneity criteria, which group neighbouring pixels with similar spectral characteristics together. Including the mosaic of curated and cloud masked Sentinel-2 images as opposed to multi-temporal mean values across 2017 yielded greater sharpness in the differentiation between image objects along the wetland boundaries. The segments were then classified based on the assumptions that wetlands occur where wetland probability according to the Potential Wetlands layer is high, and where mean NDWI and mean NDVI are higher compared to surrounding areas. Accordingly, thresholding and neighbourhood conditions were applied and iteratively adjusted through comparison with high-resolution Google Earth imagery and true- and false-colour composites of the 2017 RapidEye images across the study area. This resulted in an initial delineation threshold of 0.55 for potential wetland, to which bordering elongated objects were added as riparian vegetation. Subsequently, image objects with a mean NDWI below -0.1 were unclassified to reflect high-wetland potential areas that do not have wetland characteristics, e.g., because they have fallen dry. Additionally, objects with a potential wetland value below 0.4 were unclassified if the mean NDVI was negative or if the mean NDWI was below 0.3 . The manual editing of errors was done along the boundaries of the wetlands where adjacent objects like agricultural plots with high NDVI can be misclassified as wetland. In turn, some objects were initially not classified as wetland, as their NDWI was comparably low. These objects were added to the wetland class. During the post-processing, the shape and the surrounding landscape of true- and false-colour RapidEye scenes were compared to the delineation. Further, NDVI and NDWI values from the RapidEye imagery were considered along with the water occurrence map described below to determine whether objects were misclassified. In this approach, such post-processing increases the accuracy of the product along wetland boundaries. The final delineation product reflects wetland and nonwetland areas with a minimum mapping unit (MMU) of 0.5 ha.

\section{Surface Water Occurrence}

To account for water presence, we included an element describing spatio-temporal surface water variability into the characterization framework, as described in Fig. 4. Although 


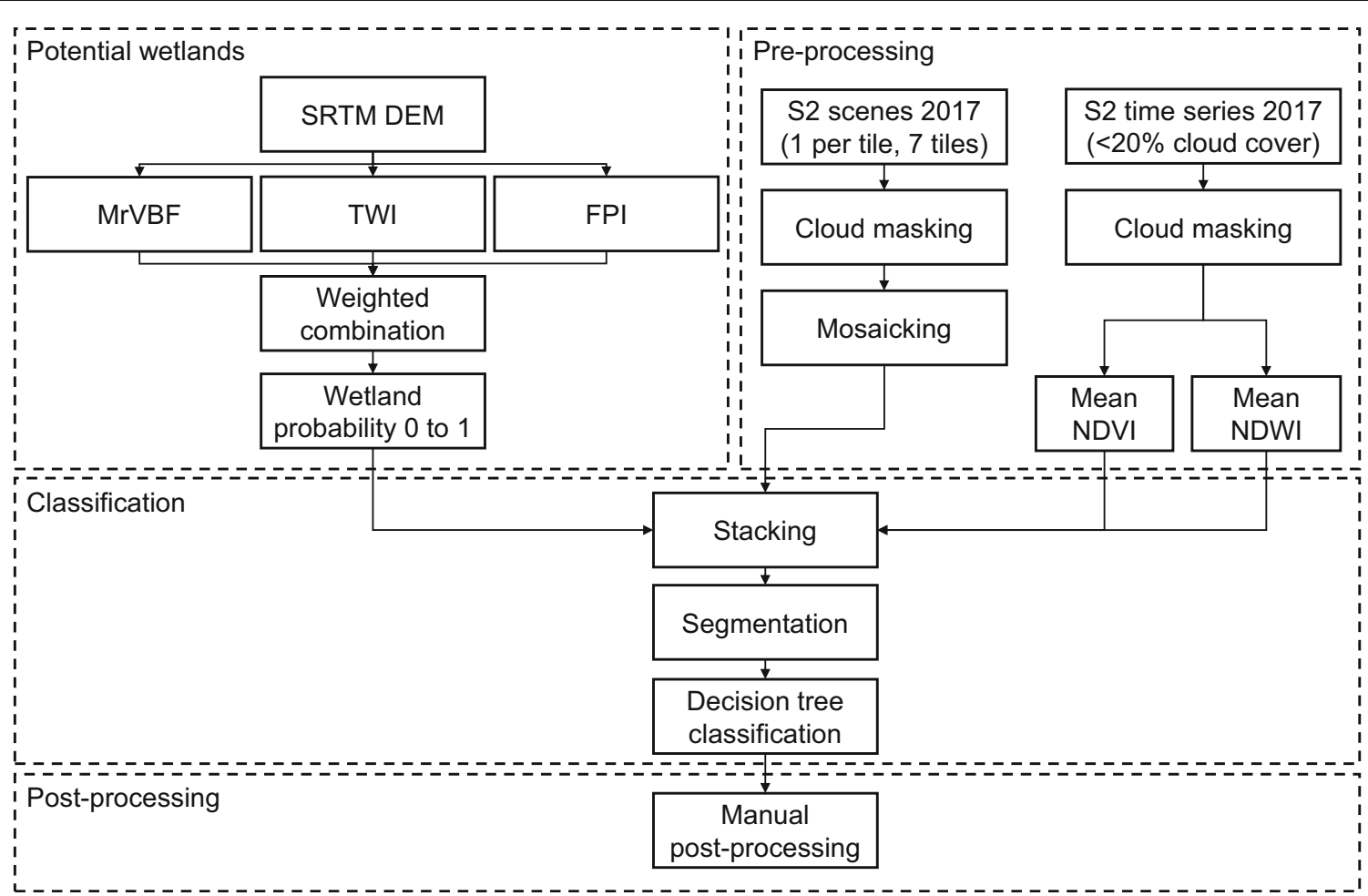

Fig. 3 Processing steps for the Wetland Delineation layer, including the calculations for Potential Wetlands with a combination of the Multiresolution Index of Valley Bottom Flatness (MrVBF), the Topographic Wetness Index (TWI) and a floodplain index (FPI), pre-processing of
Sentinel-2 (S2) images and the calculation of the Normalized Difference Vegetation Index (NDVI) and the Normalized Difference Water Index (NDWI), classification and post-processing

December 2017. The information was derived from 60 Sentinel-1 SAR images acquired in this period in ascending mode. Until February 2017, the repeat interval over the study area was 24 days and then increased to 12 days with the imagery from Sentinel-1B becoming available. The layer provides information on surface water dynamics as a measurement of water presence frequency within the three years. In order to reduce processing time and increase automation, the individual water masks were extracted in the remote sensing cloud computing platform Google Earth Engine (GEE) (Gorelick et al. 2017). Only images acquired in IW in ascending mode, VV polarization, and acquired in the same orbit were used. The GEE GRD Sentinel-1 image collection is already processed to provide backscatter coefficient (Sigma nought $\sigma^{\circ}$ ) in decibels ( $\mathrm{dB}$ ) by applying the orbit file, thermal noise removal (from July 2015 onwards), radiometric calibration and terrain correction (orthorectification) using the $30 \mathrm{~m}$ SRTM DEM to the Level-1 GRD scenes. The scenes were transformed to Gamma nought $\left(\gamma^{\circ}\right)$ through angle-correction as described by Hird et al. (2017). The focal mean with a circular radius of $30 \mathrm{~m}$ was calculated to filter noise. Surface water was then detected in each of the 60 images using an individual threshold which was calculated from the image statistics using the Otsu method, which minimizes intra-class variability between backscatter values for land and water (Otsu 1979). The results were exported from GEE, combined 
into a time stack, and the sum of water presence per pixel was calculated. We assumed that a per-pixel detection of water at least four times within the three-year observation period means the robust detection of regularly flooded pixels and the reduction of outliers due to overestimation. Therefore, pixels with a flooding frequency $<4$ were excluded. Open water bodies like Lake Kivu had higher backscatter coefficient variability due to wind-generated waves.

\section{Land Use/Land Cover Classification}

To reliably characterize the diverse wetland ecosystems and to identify different vegetation types and land uses at sufficiently high spatial resolution, we generated a (LULC) map for Rwanda at $10 \mathrm{~m}$ spatial resolution. This was achieved using a hierarchical classification scheme which follows the Food and Agriculture Organization's (FAO) Land Cover Classification System (LCCS) (Di Gregorio and Jansen 2001) for non-wetland classes and the Ramsar nomenclature (Ramsar Convention Secretariat 2000) for wetland classes in a semi-automatic unsupervised classification approach. These classification systems were selected to ensure both comparability with existing LULC classifications, and to adequately account for both temporally static and temporally dynamic classes derived from the SWO product. The full extent of Rwanda was classified to account for the importance of catchment-wetland interconnectivity which impacts hydrology and ecosystem integrity (e.g. von der Heyden and New 2003; Kotze et al. 2012; Leemhuis et al. 2017), and dictates that uplands play a crucial role in wetland management (Wood and Thawe 2013). The workflow is depicted in Fig. 5. We used Sentinel-2 images from 2016 to 2017 from the seven tiles that cover Rwanda. Only scenes with low cloud cover and from the dry season were selected, the latter to reduce the impact of phenological variability on the

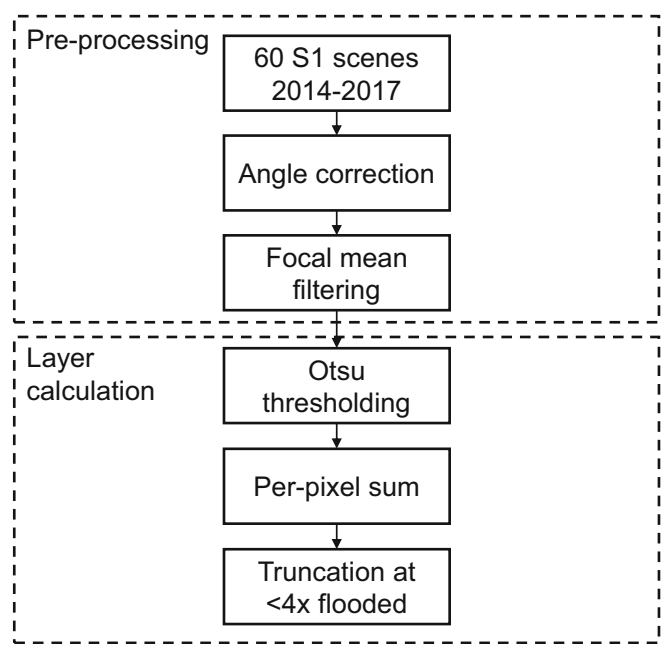

Fig. 4 Processing steps for the creation of the surface water occurrence (SWO) consisting of pre-processing and layer calculation classification. The scenes were corrected for atmospheric effects using the European Space Agency's stand-alone Sen2Cor processor (ESA 2018), and cloud and cloud shadow were masked with a semi-automatic approach. Per-tile, a mosaic was created by filling the gaps of the most cloud-free image from 2017 with the information from the images closest to the acquisition date. Preference was given to images from 2017, and only remaining unfilled gaps were closed with images from 2016. Each of the mosaics was stacked with the Potential Wetlands, SWO and Wetland Delineation layers and processed using OBIA. A multiresolution segmentation algorithm was applied in eCognition and the image objects were assigned to classes according to decision tree rules which were based on spectral, spatial, and geometric criteria. The Potential Wetlands, SWO and Wetland Delineation layers were incorporated in the ruleset to better account for a variety of wetland vegetation types. Temporally variable classes, such as seasonally flooded or wet agricultural land, seasonal/intermittent freshwater marshes, and seasonal/intermittent freshwater lakes (over 8 ha), were designated using the SWO, while other classes depended on assumptions such as the absence of cropland in national parks (shrubland class). The minimum mapping unit was 0.5 ha for all vegetation classes, whereas non-vegetation classes with typically smaller extent were mapped at 0.01 ha.

\section{Wetland Use Intensity}

WUI differentiates intensively used wetland areas, such as crop cultivation, burned areas, peat extraction, etc. from less intensively used areas, such as grazing areas for livestock farming as well as natural/semi-natural areas and permanent water. Land use intensity can be described in the dimensions of inputs (e.g. cropping frequency), outputs (e.g. yield), and changes in system properties (Erb et al. 2013). We assumed that these dimensions translate into a spectral change signal related to reflectance intensity over time and hence used a modified algorithm for time series analysis from Franke et al. (2012), the Mean Absolute Spectral Dynamics (MASD) which we adapted for wetland ecosystems. Since the aim was to analyse wetland use intensity in vegetated areas, only vegetation-sensitive bands were selected to calculate the MASD. To additionally account for a good balance between the spectral ranges, we considered: the green and red bands in the visible spectrum (band 3, $560 \mathrm{~nm}$ and 4, $665 \mathrm{~nm}$ ); two bands in the red-edge and near infrared (NIR) (band 6, $740 \mathrm{~nm}$ and 8, 833 nm); and two bands in the short-wave infrared (SWIR) (band 11, $1610 \mathrm{~nm}$ and 12, $2190 \mathrm{~nm}$ ) (Drusch et al. 2012). Hence, six bands were used in total for calculating the MASD from the time series (three bands with $10 \mathrm{~m}$ and three bands with $20 \mathrm{~m}$ spatial resolution). The formula for calculating the MASD from Franke et al. (2012) is as follows: 
Fig. 5 Processing steps for the creation of the Land Use/Land Cover (LULC) classification layer consisting of pre-processing of Sentinel-2 (S2) images and their classification, incorporating the Potential Wetlands, the Wetland Delineation and the Surface Water Occurrence (SWO) layers
$M A S D=\frac{1}{m-1} \sum_{t=1}^{m-1}\left(\frac{1}{n} \sum_{i=b}^{n}\left|\rho_{i}^{t}-\rho_{i}^{t+1}\right|\right)$

whereby, $\mathrm{m}=$ number of observation dates, $\mathrm{t}=$ observation date, $n=$ number of spectral bands, $b=$ spectral band, $\rho=$ pixel reflectance.

The processing steps for the creation of the WUI layer are shown in Fig. 6. Cloud and cloud shadow can cause artifacts in the resulting WUI layer. Due to frequent and extensive cloud cover over Rwanda, only a maximum of eight Sentinel-2 images per tile with very low cloud cover was selected for the year 2017. The WUI product was created per Sentinel-2 tile whereby cloud and cloud shadow were first masked in each image in the time series using a semi-automatic approach. As a threshold, the minimum number of cloud-free observations per pixel was set to three, meaning that the WUI product was only produced for those pixels with three to eight cloud-free observations in 2017.

\section{Accuracy Assessment}

The accuracy of each of the wetland delineating and characterizing layers was assessed in a different way according to their specific characteristics, main sources of error and data availability. Table 1 summarises the error sources and assessment approaches followed.
The assumption that wetland landscapes can be distinguished from uplands through a significant difference in topography and vegetation cover forms the basis of the applied delineation approach. This assumption was verified during a field survey in July 2018 with 12 transects through wetlands between Kigali and the eastern border of Rwanda, between Kigali and the Rugezi wetland in the far north, and along the western-lying route between Ruhengeri and Kigali. Coordinates were recorded with a handheld GPS, while digital photos were taken, and sketches were made

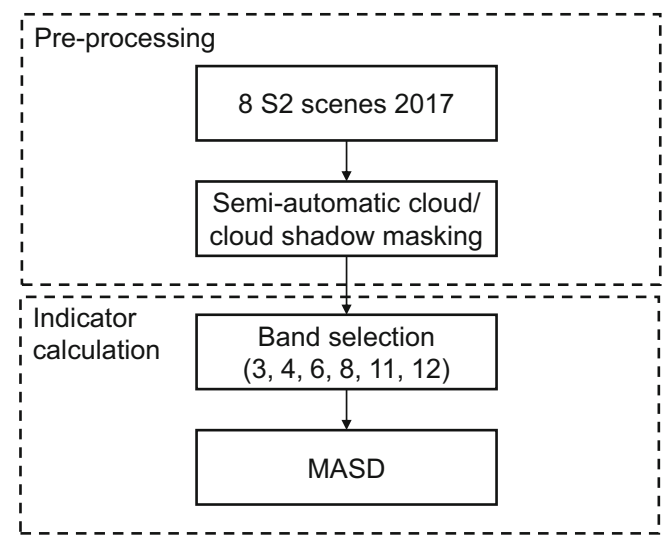

Fig. 6 Processing steps for the creation of the Wetland Use Intensity (WUI) layer consisting of pre-processing and Mean Absolute Spectral Dynamics (MASD) calculation 
Table 1 Summary of the layer's main sources of error and the validation approach selected accordingly

\begin{tabular}{|c|c|c|}
\hline Layer & Main sources of error & Validation approach \\
\hline Wetland Delineation & $\begin{array}{l}\text { Over- and underestimation of wetland width along } \\
\text { the boundaries where object characteristics inside } \\
\text { and outside of wetlands are similar. }\end{array}$ & $\begin{array}{l}\text { Comparison of automatically derived to manually } \\
\text { delineated wetland surface area in a random sample } \\
\text { of } 255 \text { wetland segments of } 200 \mathrm{~m} \text { length. }\end{array}$ \\
\hline $\begin{array}{c}\text { Surface Water } \\
\text { Occurrence }\end{array}$ & $\begin{array}{l}\text { Non-detection of surface water presence in the backscatter } \\
\text { signal (waves, mixed pixels in narrow water bodies) } \\
\text { and false detection of surface water presence due to an } \\
\text { inaccurate threshold value. }\end{array}$ & $\begin{array}{l}\text { Comparison of detected water surface on } 15 / 06 / 2017 \\
\text { and } 09 / 07 / 2017 \text { to manually delineated water surfaces } \\
\text { in five RapidEye tiles from } 20 / 06 / 2017,10 / 07 / 2017 \text {, } \\
\text { and } 11 / 07 / 2017 \text {. }\end{array}$ \\
\hline $\begin{array}{l}\text { Land Use/Land } \\
\text { Cover }\end{array}$ & Confusion of land use/land cover classes. & $\begin{array}{l}\text { Confusion matrix for aggregated stable classes, using } \\
\text { a stratified random sample of points interpreted against } \\
\text { a mosaic of RapidEye images from June and July } 2017 .\end{array}$ \\
\hline $\begin{array}{l}\text { Wetland Use } \\
\text { Intensity }\end{array}$ & $\begin{array}{l}\text { Inaccurate representation of use intensity in areas } \\
\text { with few clear-sky observations. }\end{array}$ & $\begin{array}{l}\text { Plausibility assessment through comparison of layer value } \\
\text { patterns for different land uses with distinct use intensities } \\
\text { (e.g., lowland rice with high and protected areas with low } \\
\text { use intensities). }\end{array}$ \\
\hline
\end{tabular}

at points of interest. As a quantitative assessment, a conventional random sampling-based confusion matrix was found to not account well for the actual issue of over- and underestimation of area at the wetland boundaries. Therefore, a validation strategy comparing randomly selected slices of the delineation product with manually derived wetland from high-resolution satellite imagery was adopted. Centrelines, defining the linear centre locations within the delineation polygons, were calculated and subdivided into segments of $200 \mathrm{~m}$ length. Then, a random sample of the size of $1 \%$ of all segments was drawn. After cleaning the overlapping wetland slices, a total of 255 segments was considered. Perpendicular to the centreline segments, we generated rectangles with the width of the delineation plus $100 \mathrm{~m}$. Wetland boundaries were manually extracted within the rectangles using RapidEye imagery pre-processed to the 3A product, acquired between June and August 2017. The delineated wetland area was then compared to the manually extracted one and the percentage of over- and underestimation was determined. Over- and underestimation are defined as the positive or negative deviation in area of the delineated from the manually determined wetland per wetland segment in percent.

Since detailed hydrological information was not available for the whole country for the period 2014 to 2017 , the SWO layer was validated with a simplified version of the validation approach applied to the Global Surface Water Dynamics product by Pekel et al. (2016). Their accuracy assessment included the comparison of randomly selected individual water masks with high spatial resolution remote sensing imagery as well as ancillary hydrological data. For the water masks produced in this study, manually digitized surface water from cloud-free RapidEye tiles from 20/06/2017, 10/07/2017, and 11/07/ 2017 were compared to the closest dates of water extraction, namely $15 / 06 / 2017$ and $09 / 07 / 2017$. The tiles were selected to cover different wetland landscape types across Rwanda as explained in Introduction and taking the agroclimatic zones for guidance (cf. Figure 7). The validation thus included areas of flat topography with large water bodies such as Lake Kivu and the Akagera wetland complex in the far west and far east of Rwanda (tiles 5 and 4), relatively wide and continuously flooded wetlands such as the Muhazi wetland east of Kigali (tile 2), as well as narrower wetlands west of the Capital (tiles 1 and 3). The overlap of digitized and detected surface water was calculated for the respective tiles. As the LULC classification intentionally comprises temporally dynamic classes which cannot be validated at one particular point in time, for the accuracy assessment, all subclasses were aggregated to the main classes bare soil, broad-leaved forest, mosaic cropland, needle-leaved forest, sand, built-up, and water. They were validated against 1,258 points from a stratified random sampling scheme which were visually interpreted against a cloud-free RapidEye mosaic from June to July 2017. The classified and reference points were compared in a confusion matrix and user's, producer's, and overall accuracy were determined.

Being a multi-temporal product, the WUI could not be validated quantitatively, but was assessed for plausibility through comparison to distinct land uses such as lowland rice agriculture, sugarcane cultivation (high use intensity), and protected natural/semi-natural areas (low use intensity).

\section{Results and Discussion}

The wetland delineation and characterization layers are shown in Fig. 8 and presented in the following section. 
Fig. 7 Surface Water Occurrence (SWO) validation layout based on the comparison with manually delineated surface water from RapidEye reference tiles from 20/ 06/2017, 10/07/2017 and 11/07/ 2017 with zoom-ins on the tiles
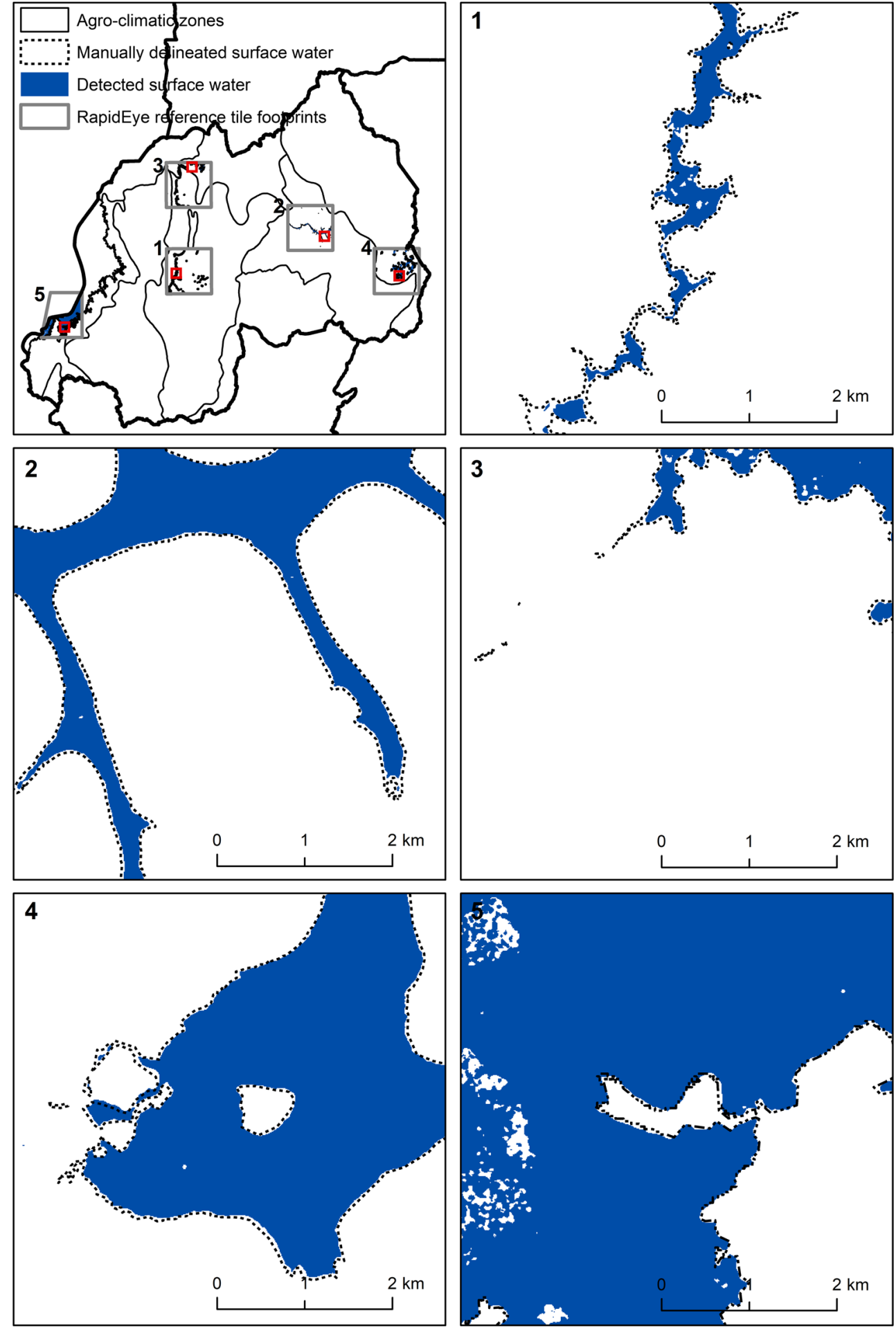

\section{Wetland Delineation}

The wetland extent delineated using the two-step approach is 471,458 ha, which accounts for $18.6 \%$ of Rwanda's total area. With major water bodies derived from the Global Lakes and Wetlands Database (GLWD) Level-1 data (Lehner and Döll 2004) excluded, it is $14.3 \%$ of Rwanda's area. This number exceeds the extent determined through the 2008 wetland survey $(222,421$ ha, REMA 2008$)$ by more than a third. The comparison of the 255 randomly selected wetland slices and reference wetland area digitized from 2017 RapidEye imagery resulted in a median overestimation of wetland area of $15.3 \%$. This slight tendency for overestimation is also reflected in the median producer's accuracy of 
Fig. 8 Wetland delineation and characterization framework products created for Rwanda: (a) Wetland Delineation (2017), (b) Surface Water Occurrence (SWO) (2014-2017), (c) Land Use/Land Cover (LULC) classification according to the Ramsar classification scheme (2017), and (d) Wetland Use Intensity (WUI) (2017)
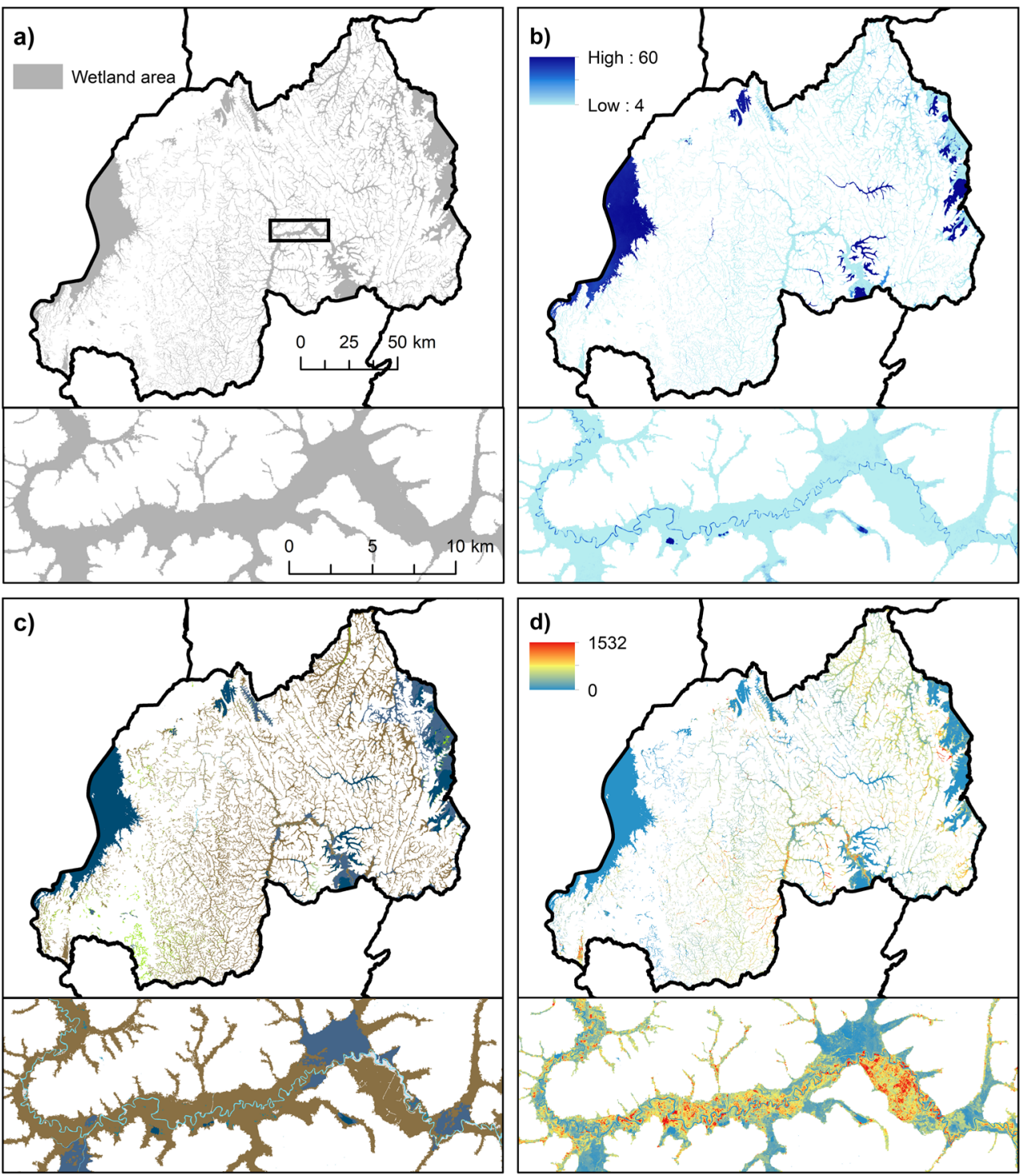

\section{Ramsar classes}

2 - Ponds; includes farm ponds, stock ponds, small tanks; (generally below 8 ha)

4 - Seasonally flooded agricultural land (including intensively managed or grazed wet meadow or pasture)

E - Sand, shingle or pebble shores; includes sand bars, spits and sandy islets; includes dune systems and humid dune slacks

$\mathrm{M}$ - Permanent rivers/streams/creeks; includes waterfalls

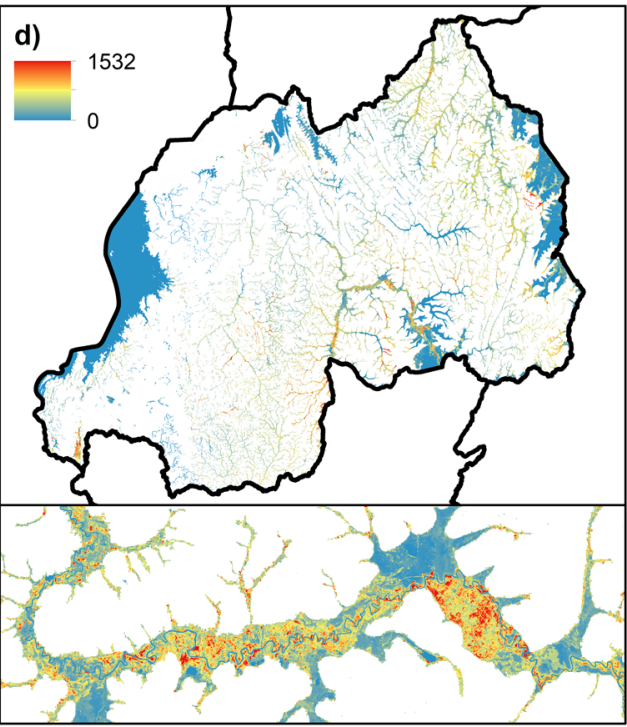

O-Permanent freshwater lakes (over 8 ha) includes large oxbow lakes

Ts - Seasonal/intermittent freshwater marshes/pools on inorganic soils; includes sloughs, potholes, seasonally flooded meadows, sedge marshes W - Shrub-dominated wetlands; shrub swamps, shrub-dominated freshwater marshes, shrub carr, alder thicket on inorganic soils

$\mathrm{Xf}$ - Freshwater, tree-dominated wetlands; includes freshwater swamp forests, seasonally flooded forests, wooded swamps on inorganic soils
$90.8 \%$ against the median user's accuracy of $73.9 \%$ (see boxplots in Fig. 9).

\section{Surface Water Occurrence}

The overlap of digitized and detected surface water differs between the selected RapidEye tiles, as depicted in Table 2. The percentage overlap was highest for the large water bodies in tiles 4 and 5, whereas it was lowest for the narrow wetlands and water bodies in tiles 1 and 3, although the accuracy of surface water detection in tile 3 was as high as $79.7 \%$. The total percentage overlap is high with $93.8 \%$.

Figure 10 shows a zoom on the SWO layer in an area south of Kigali ( $a$ and $b$ ) compared to the JRC Global Surface Water Dynamics dataset (c) (Pekel et al. 2016). The latter is derived from the Landsat and Sentinel-2 archives until 2019. In comparison, the continuously flooded parts are represented relatively similarly. In contrast, the representation of seasonally or periodically flooded wetland areas is more nuanced in the SWO layer. 
Fig. 9 Boxplots of (a) user's and (b) producer's accuracy for the generated wetland delineation evaluated against manually digitized wetland area

\section{Land Cover Classification}

User's and producer's accuracies for each class of the aggregated LULC classification are high with only the sand class dropping below $80 \%$ for both accuracies, and urban for the user's accuracy. This can be explained by the mostly small patches covered by these classes relative to the spatial resolution of the input satellite imagery. Individual class accuracies are displayed in Table 3 and amount to an overall accuracy of $93.2 \%$. The classification shows that 304,324 ha of all wetland area is occupied by seasonally flooded or wet agricultural land, which is $64.6 \%$ of wetland area and $84.0 \%$ excluding lakes. This high percentage reflects Rwanda's increased use of wetlands for agricultural activities, which is driven by government policies aimed at the progressive exploitation of wetlands. These percentages exceed the numbers given by the 2008 wetland survey, which describe $53 \%$ of wetlands as under cultivation and $6 \%$ as fallow (REMA 2008). However, the wetland agriculture class used here includes intensively managed as well as grazed wet meadow and pasture.

Table 2 Percentage overlap of detected surface and water digitized from the 5 RapidEye tiles

\begin{tabular}{lllllll}
\hline Tile no. & 1 & 2 & 3 & 4 & 5 & $1-5$ \\
\hline Overlap (\%) & 47.3 & 88.6 & 79.7 & 94.8 & 95.9 & $\mathbf{9 3 . 8}$ \\
\hline
\end{tabular}

b)

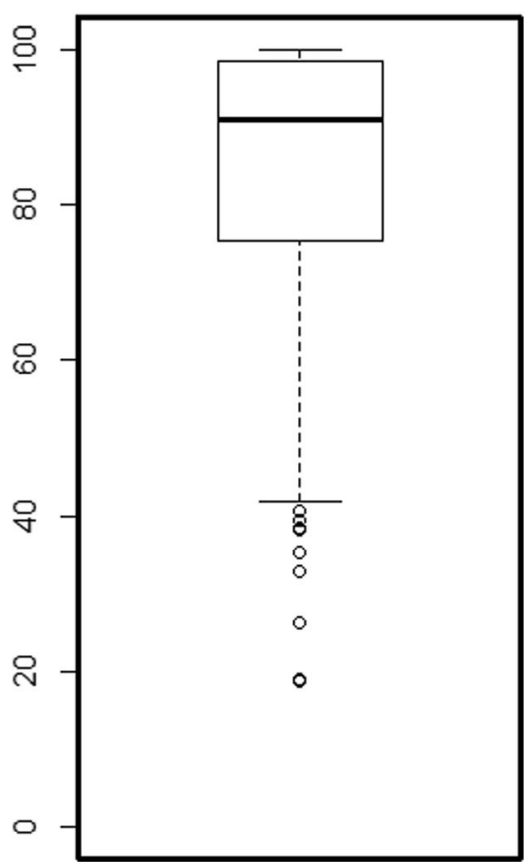

\section{Wetland Use Intensity}

The WUI layer is a deduced indicator showing changes in reflectance in the selected wetland-relevant bands across multiple satellite scenes. It is a time series product and could not be validated quantitatively, but only qualitatively. On the local scale, upon verification for known locations such as the rice irrigation scheme in Fig. 8d), this layer reflects intensive agricultural use with high values, as well as stable semi-natural areas.

On the national scale, a comparison of WUI and wetland area aggregated to gridded values at $8 \times 8 \mathrm{~km}$ in Fig. 11 shows that south of Kigali and in the northeast of the country the use is most intensive relative to wetland extent. On both scales, the indicator is therefore suited as a basis for further detailed investigation. As a comparison between time steps, the increase or decrease of land use pressure, mostly through agriculture, onto wetlands can be derived on both scales.

\section{Framework Application for Informed Decision-making}

We designed this Copernicus-based framework to address four major problems of geodata-related tropical wetland management, using Rwanda as a demonstrator. We laid out a conceptual framework that can be adapted and deployed in other countries and regions and that can be applied according to respective user needs. Despite the variability of wetland boundaries, they could be detected with relatively high confidence. This was facilitated by the distinct appearance of 


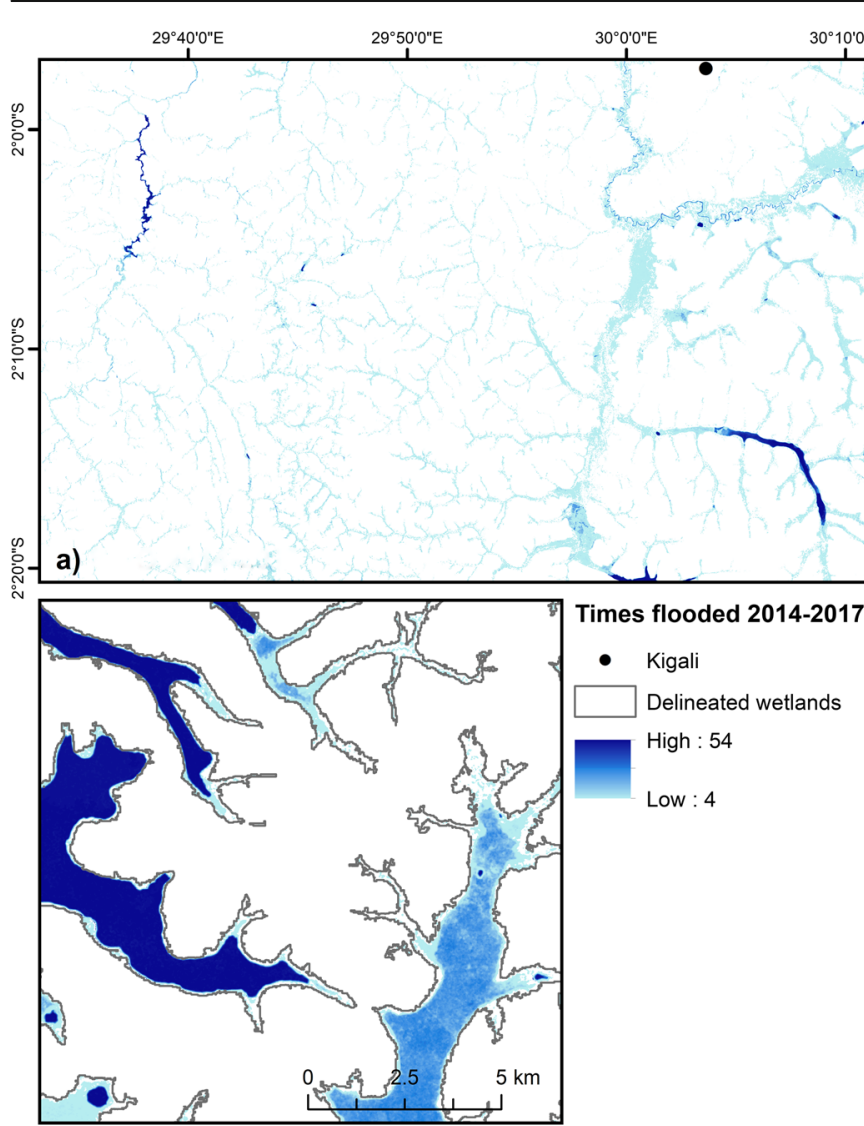

b)
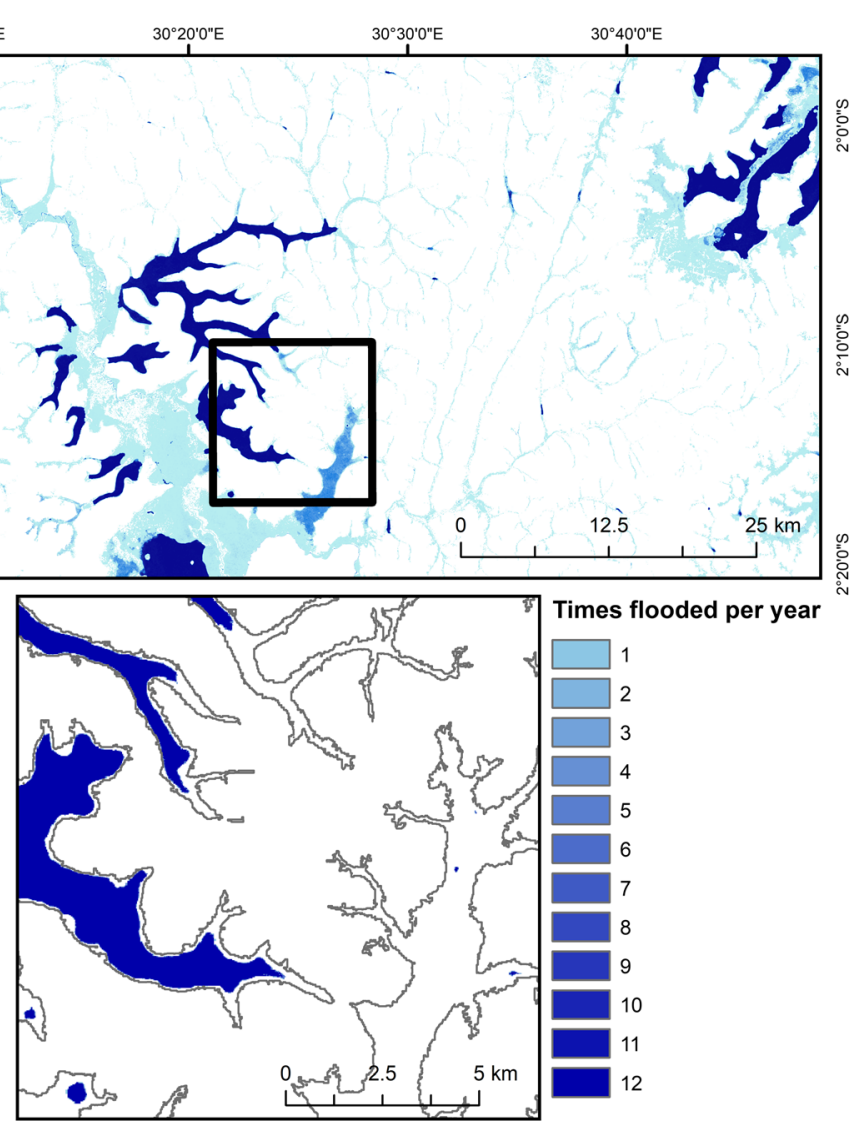

c)

Fig. 10 (a) and (b) show Surface Water Occurrence (SWO) compared to (c), the Joint Research Center (JRC) Global Surface Water seasonality based on the Landsat archive and Sentinel-2 imagery until 2019 (Pekel et al. 2016)

Rwandan wetland landscapes with respect to their use. Since the vegetation zonation is particular and reflected in high spatial resolution satellite imagery, it could be considered a valid indicator for wetland delineation. The combination of topographic and surface reflectance data makes the approach robust. Depending on whether wetland landscapes are situated in more accentuated topography or are more characterized by their vegetation and use compared to their surroundings, the

Table 3 Confusion matrix of the LULC classification's aggregated classes bare soil, broad-leaved forest, mosaic cropland, needle-leaved forest, sand, built-up and water, giving per-class user's, producer's accuracy, mean user's and producer's accuracy, and overall accuracy

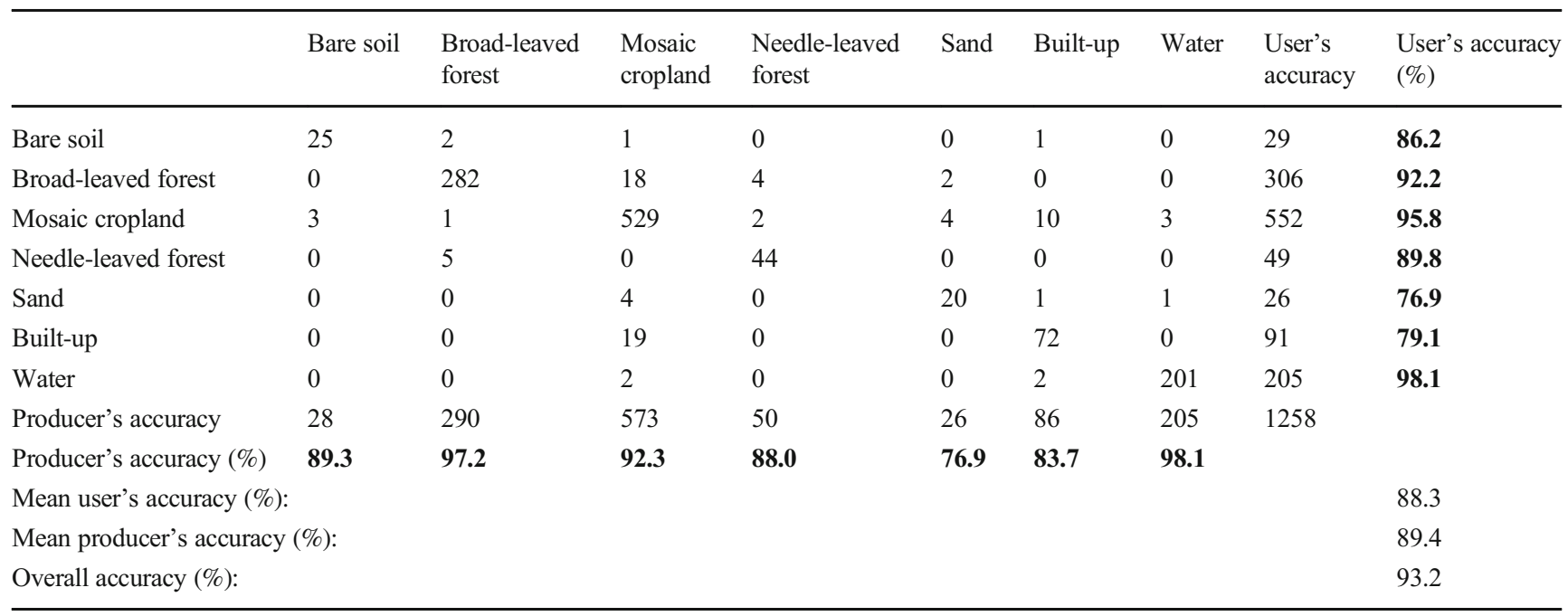

The bold entries should visually help distinguish between the class shares (Bare soil,..., Water) and the accuracy measures 
Fig. 11 (a) Total wetland area in $\mathrm{km}$ and (b) mean Wetland Use Intensity (WUI) within grid cells of $8 \times 8 \mathrm{~km}$ size across Rwanda
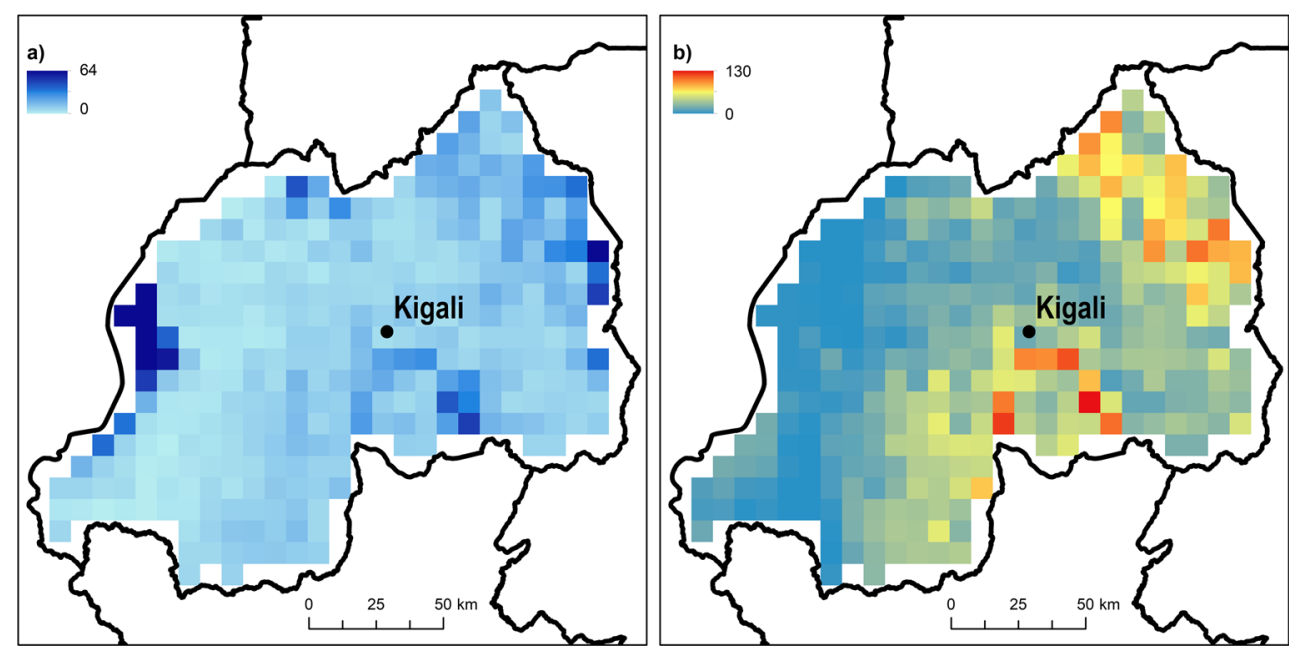

approach can rely slightly more on the one or on the other aspect. It thus allowed the delineation both in the flatter Eastern Lowland and in the Congo-Nile Watershed Divide with its accentuated topography. Additionally, an objectbased approach accounting for the relative difference in spectral characteristics of lowland and upland addresses the challenge of trying to describe wetlands with a concise spectrum of reflectance values and to classify them accordingly. It can therefore be expected that the delineation approach is applicable in a wide variety of wetland landscapes across East Africa. However, the thresholds set in the decision tree classification have to be adjusted for other areas. Also, the manual postprocessing requires additional user input. That said, the scope of the post-processing along the wetland boundaries as a quality control step is limited. It can therefore be considered as a cost-efficient approach compared to comprehensive field surveys or manual delineation. The use of a higher spatial resolution DEM, if available, is optional. The SRTM DEM's spatial resolution was found to be sufficiently high across the different wetland landscapes.

The advantage of defining wetland boundaries before characterizing wetlands is clear for the SWO, for which false positives caused by topographic effects in the surrounding hilly landscape could thus be eliminated. That said, inaccuracies arise from the use of the automatic Otsu thresholding algorithm. Over our observation period of more than three years, these could efficiently be reduced by only taking regularly flooded pixels into account. A shorter observation period may cause outliers to have a stronger impact on the product. Although the SWO layer generally captures surface water dynamics in more detail than other commonly used products, the lowest accuracies are achieved in narrow and elongated water features. Also, wind-generated waves hinder correct water detection on large water bodies. The latter issue can be addressed by combining the SWO layer with water body data like the GLWD by Lehner and Döll (2004). For the former, the lack of available and accessible higher spatial resolution SAR data is a limitation.

The use of the Ramsar classification scheme for LULC mapping fills a gap in large-scale wetland assessment, since the LULC products available for East Africa do not account well for wetland ecosystems. The Ramsar wetland classes are inherently relevant in ecosystem assessment and can be directly used for the respective reporting purposes. However, although the LULC classification shows good accuracies, the accuracy assessment represents a validation of a summary of all classes but does not specifically account for the temporally dynamic classes created by incorporating the SWO layer. Error propagation should therefore be considered.

The WUI layer is not related to specific wetland management or agricultural practices. But it reflects all forms of management practices that affect vegetation reflectance characteristics through time. Its biggest drawback in this study was the reliance on the availability of multi-temporal optical imagery consistently throughout 2017 . In order to prevent the impact of cloud and cloud shadow on the result, they were masked thoroughly and each of the scenes was quality controlled. In the future, this should be done using improved masking algorithms, to increase automation and include more observations per pixel. This will improve the layer's capacity to capture change in reflectance and therefore more accurately map wetland use intensity.

The use of satellite data with comparable spatial resolution and within the same time span supports the consistency of the produced information throughout all layers. Thus, the layers can be used individually or combined, depending on user needs. Several processing steps still require some manual work or cost-intensive and complex software, such as the post-classification of the wetland delineation, the LULC classification, and the calculation of the WUI layer. However, the automation of most steps, and in the case of the SWO implementation in the GEE environment, facilitates the reproduction of the layers for shorter or longer periods than presented 
in this study. Also, with a repeat production of the layers, changes in the physical characteristics of wetlands can be tracked and monitoring schemes developed. Based on the static potential wetlands layer, actual wetland area can be redelineated after some years. Since changes in use intensity and resulting hydrological effects typically occur within shorter timespans, the analysis of SWO and WUI should be repeated on a regular basis, for example annually or separately for growing seasons. Medium- and short-term changes can be analysed against the longer-term trend. To derive the latter, Landsat imagery could be used for the LULC and WUI layers to be able to go back further in time. Nevertheless, the issue of little or non-existing validation data needs to be solved to ensure sufficiently high layer accuracy.

The spatial data requirements arising from the problem statements formulated in Introduction could all be addressed by the four layers. The differing degree to which each layer responds to the respective requirement is visualized in Table 4, using parentheses for a lower degree, regular font, and bold font for the highest degree. While all layers provide spatially explicit and disaggregated information (requirement 1) across the whole country at a spatial resolution of 10 to $30 \mathrm{~m}$, spatio-temporal variability (requirement 2 ) is most precisely reflected by the SWO and the WUI layers. Both the Delineation and the LULC classification incorporate this variability, the former through the fact that the distinctiveness of vegetation-indicated boundaries is usually maintained throughout the hydrological cycle, the latter as it incorporates the SWO layer. SWO and WUI are a priori time-series products and can be adapted to user needs, by stretching out the observation period to derive a longer-term baseline, or by reducing it to focus on particularly limited periods, if sufficient high-quality images exist to produce the respective layer. The approaches used to create LULC classification, SWO, and WUI contain a high degree of automation, allowing repetition for the same area or application for another area of interest while sustaining comparability (requirement 3 ). In turn, to improve layer quality, it proved useful to include a manual post-processing step in the delineation of wetland area, slightly lessening the comparability to a re-assessment. However, since more substantial changes in wetland boundaries often take years to manifest (unless caused by short-term interventions), the uncertainty introduced by the application of a manual step is likely to be outweighed by such underlying trends. Because the delineation represents longer-term trends as a consequence of drivers of wetland change, it is only of limited suitability to quantify these drivers (requirement 4). Altered hydrology is both a result of wetland change and a variable whose modification leads to changes in wetland ecosystems. The SWO layer allowed to identify various locations across Rwanda where surface water hydrology is influenced by damming for irrigation or to operate hydropower stations and where further monitoring is advisable. The SWO layer can therefore serve as an indirect indicator, whereas LULC and WUI, as well as the combination of both, are capable of directly depicting sites of intensive agricultural wetland use, which is the main driver of wetland change. Large parts of the wetland landscapes in the centre and in the northeast of Rwanda could be characterized as being used for intensive agriculture. This reflects the government's efforts to counteract food insecurity by increasing wetland area under cultivation as well as by implementing large-scale irrigation schemes. The adaptation of the WUI methodology for SAR imagery could furthermore enhance its use potential for detecting and monitoring such areal expansion of agricultural land in wetlands and agricultural intensification.

The presented outputs for Rwanda cannot form the basis for legally binding boundary setting without prior investigation at the place of interest, e.g., in the sense of a cadastral land register. However, they enable incorporation of EO-derived data at scales relevant to policy and planning. Our results can update and expand the existing wetland inventory and establish a continuous monitoring scheme, within which the layers and layer combinations are re-evaluated on a regular basis to detect trends pointing to the improvement or to the degradation of wetlands. This is of particular importance for the institutions and organisations concerned with wetland management as named in Section 2.1. On the one hand, institutions involved in the agricultural development of the country can use such data to determine target areas for agricultural exploitation and intensification. On the other hand, they and their counterparts tasked with safeguarding environmental integrity, can monitor environmental impacts on a larger scale. Beyond national wetland management, the SWO layer directly caters towards the SDG indicator 6.6.1.

Whereas in the context of development and certain applied research projects, there has been a shift towards accounting for the complexity of landscapes with their different land uses and stakeholders (Wood et al. 2013), applied remote sensing research seems to prefer sectoral approaches. With respect to wetlands, this often concerns either their conservation (or degradation) or their efficient use, particularly for agricultural production. Despite the evident need for those studies and development of specific methods for each application, a change of perspective towards stronger inter-sectoral EO research as regards content, and towards the flexible production of spatial information products for wetlands as regards methods, is beneficial. This is especially true in many subSaharan African countries where environmental protection and food security constitute a major field of conflict. Using the example of Rwanda, a modular framework for wetland characterization provided relevant information both for environmental protection and for food production. These products are available on the national scale and their consistency allows for their combination with additional information, even more so if complemented by further modules. Spatial information 
Table 4 Requirements formulated in Section 1 with the framework layers that cater for them symbolized with parentheses, regular font, and bold font in ascending order of degree

\begin{tabular}{|c|c|}
\hline Requirements & Layer \\
\hline 1. Provision of spatially explicit information & Delineation, SWO, LULC, WUI \\
\hline 2. Representation of spatio-temporal variability & Delineation, SWO, LULC, WUI \\
\hline 3. Comparability of data and repeatability of approaches & Delineation, SWO, LULC, WUI \\
\hline 4. Quantification of information on drivers of wetland change & (Delineation,) SWO, LULC, WUI \\
\hline
\end{tabular}

The bold font symbolizes the degree to which the layers address identified issues

produced by sectoral or regional initiatives, such as through the GEOclassifier or the GlobWetland Africa GW-A toolbox, for example, can be integrated as optional modules or as an additional data source. So far, a range of information needs could be met with the provided dataset. Although not all factors were covered, these can serve as indicators of change in the hydrology, agriculture, and ecology sub-groups. This national dataset represents a good basis for reporting to international conventions and update wetland status. Nevertheless, to understand changes in wetland landscapes, information on underlying drivers, pressures and management responses are essential and needed to frame all analyses.

\section{Conclusions}

Awareness of the importance of wetlands on all scales has increased over the last decades because of their capacity to sequester large amounts of carbon and thus contribute to climate change mitigation, as well as to moderate the effects of climate change on hydrology and the international food system. On the national level, operational tools for coherent and comprehensive information generation are still lacking, leaving a gap between general knowledge and actual spatial planning. This is particularly accentuated in sub-Saharan Africa where the poorest are typically the first to suffer from the mismanagement of resources.

A rapidly growing population have become one of the biggest challenges in Rwanda and the need to reconcile environmental protection with food production is paramount. The political will has manifested in the ratification of several multilateral agreements as well as in national legislation. As a step towards closing the policy-management gap, this study presents a conceptual framework based on spatial information needs for large-scale agricultural planning and environmental protection from remotely sensed data. The use of freely available imagery, mostly free software and automated workflows lowers the barrier to integrate Earth observation into wetland management. A modular setup of the framework provides the basis for a range of applications, like the countrywide consistent delineation of wetland landscapes and the identification of wetlands intensively used for agriculture, or cropland expansion in protected areas. In the tropical environments of East
Africa, the SAR-based SWO layer provides a viable and flexible option to approach hydrological dynamics as compared to products derived from optical data. The use of different wellestablished LULC classification nomenclatures provides comparability and consistency with other LULC products on various scales and beyond country boundaries, whereas the WUI layer introduces a dynamic product which can be used to identify shorter-term changes in wetlands. Different combinations of all data layers increase their robustness, versatility, and allow deriving additional information. Furthermore, it is encouraged to complement the presented data modules by others with comparable characteristics concerning spatial and temporal resolution, to address more specific questions.

In applied Earth observation science for wetlands, there is a need to change perspectives from the sectoral view towards more integrative approaches, including both the environmental protection and the food production aspects. This is a trend in development projects and wetland management programs and should be reflected in operational remote sensing approaches. As demonstrated for Rwanda, likewise there is a need to change perspectives in wetland mapping from rigidly defined wetland classes towards a flexible characterization that is adaptable to multiple large-scale planning issues. Thus, monitoring and guidance for targeted interventions can be supported.

Supplementary Information The online version contains supplementary material available at https://doi.org/10.1007/s13157-021-01468-9.

Acknowledgements Feedback on data needs and the data layers were kindly provided by the Bureau of Statistics, Rwanda (NISR), the Rwanda Environment Management Authority (REMA), the Albertine Rift Conservation Society (ARCOS) and the Association pour la Conservation de la Nature au Rwanda (ACNR).

Author Contributions conceptualization, A.N., K.H., S.S. and S.Z.; methodology, S.S.; validation, K.H. and S.S.; formal analysis, J.F., K.H., N.C. and S.S; writing - original draft preparation, S.S.; writingreview and editing, A.N., A.S., F.T., J.F., K.H., N.C. S.Z. and S.S.; project administration, A.S., F.T., J.F. and K.H.; funding acquisition, A.S.

Funding This research was funded through the Copernicus-based Detection and Monitoring of tropical Wetlands (DeMo-Wetlands) by the German Aerospace Center (DLR) with funds from the German Federal Ministry for Economic Affairs and Energy under grant no. FKZ 50EE1537. 
Data Availability The datasets generated during the current study are available in the Zenodo repository, https://doi.org/10.5281/zenodo. 4326702

Code Availability Not applicable.

\section{Declarations}

Conflicts of Interest/Competing Interests The authors declare no conflict of interest. The funders had no role in the design of the study; in the collection, analyses, or interpretation of data; in the writing of the manuscript, or in the decision to publish the results.

Ethics Approval Not applicable.

Consent to Participate Not applicable.

Consent for Publication Not applicable.

Open Access This article is licensed under a Creative Commons Attribution 4.0 International License, which permits use, sharing, adaptation, distribution and reproduction in any medium or format, as long as you give appropriate credit to the original author(s) and the source, provide a link to the Creative Commons licence, and indicate if changes were made. The images or other third party material in this article are included in the article's Creative Commons licence, unless indicated otherwise in a credit line to the material. If material is not included in the article's Creative Commons licence and your intended use is not permitted by statutory regulation or exceeds the permitted use, you will need to obtain permission directly from the copyright holder. To view a copy of this licence, visit http://creativecommons.org/licenses/by/4.0/.

\section{References}

Amler E, Schmidt M, Menz G (2015) Definitions and mapping of East African wetlands: a review. Remote Sens 7:5256-5282. https://doi. org/10.3390/rs 70505256

van Asselen S, Verburg PH, Vermaat JE, Janse JH (2013) Drivers of wetland conversion: a global meta-analysis. PLoS One 8:e81292. https://doi.org/10.1371/journal.pone.0081292

Athmania D, Achour H (2014) External validation of the ASTER GDEM2, GMTED2010 and CGIAR-CSI- SRTM v4.1 free access Digital Elevation Models (DEMs) in Tunisia and Algeria. Remote Sens 6:4600-4620. https://doi.org/10.3390/rs6054600

Berger M, Moreno J, Johannessen JA et al (2012) ESA's sentinel missions in support of Earth system science. Remote Sens Environ 120: 84-90. https://doi.org/10.1016/j.rse.2011.07.023

Beuel S, Alvarez M, Amler E et al (2016) A rapid assessment of anthropogenic disturbances in East African wetlands. Ecol Ind 67:684 692. https://doi.org/10.1016/j.ecolind.2016.03.034

Beven KJ, Kirkby MJ (1979) A physically based, variable contributing area model of basin hydrology / Un modèle à base physique de zone d'appel variable de l'hydrologie du bassin versant. Hydrol Sci Bull 24:43-69. https://doi.org/10.1080/02626667909491834

Böhner J, Selige T (2006) Spatial prediction of soil attributes using terrain analysis and climate regionalisation. Göttinger Geographische Abh 115:13-28

Borah SB, Sivasankar T, Ramya MNS, Raju PLN (2018) Flood inundation mapping and monitoring in Kaziranga National Park, Assam using Sentinel-1 SAR data. Environ Monit Assess 190:520. https:// doi.org/10.1007/s10661-018-6893-y
Buchhorn M, Lesiv M, Tsendbazar N-E et al (2020) Copernicus global land cover layers - Collection 2. Remote Sens 12:1044. https://doi. org/10.3390/rs12061044

Bwangoy J-RB, Hansen MC, Roy DP et al (2010) Wetland mapping in the Congo Basin using optical and radar remotely sensed data and derived topographical indices. Remote Sens Environ 114:73-86. https://doi.org/10.1016/j.rse.2009.08.004

Cambrezy L (1981) Conquête des marais au Rwanda et dynamique de population. Rural 83:45-67. https://doi.org/10.3406/rural.1981.2664

Carrera-Hernández JJ (2021) Not all DEMs are equal: An evaluation of six globally available $30 \mathrm{~m}$ resolution DEMs with geodetic benchmarks and LiDAR in Mexico. Remote Sens Environ 261:112474. https://doi.org/10.1016/j.rse.2021.112474

Chapman LJ, Balirwa J, Bugenyi FWB et al (2001) Wetlands of East Africa: Biodiversity, exploitation, and policy perspectives. Biodivers Wetl 2:101-131

Darrah SE, Shennan-Farpón Y, Loh J et al (2019) Improvements to the Wetland Extent Trends (WET) index as a tool for monitoring natural and human-made wetlands. Ecol Ind 99:294-298. https://doi.org/10. 1016/j.ecolind.2018.12.032

Davidson NC (2014) How much wetland has the world lost? Long-term and recent trends in global wetland area. Mar Freshw Res 65:934. https://doi.org/10.1071/MF14173

De Grandi GF, Mayaux P, Malingreau JP et al (2000) New perspectives on global ecosystems from wide-area radar mosaics: Flooded forest mapping in the tropics. Int J Remote Sens 21:1235-1249. https:// doi.org/10.1080/014311600210155

Demont M (2013) Reversing urban bias in African rice markets: A review of 19 National Rice Development Strategies. Glob Food Sec 2:172181. https://doi.org/10.1016/j.gfs.2013.07.001

Developed for ESA by CS in partnership with Brockmann Consult CS ROMANIA, Telespazio Vega Deutschland, INRA and UCL (2018) ESA Sentinel 2 Toolbox | STEP

Di Gregorio A, Jansen LJM (2001) Land cover classification system (LCCS): classification concepts and user manual; for software version 1.0. FAO, Rome

Dixon AB, Wood AP (2003) Wetland cultivation and hydrological management in eastern Africa: Matching community and hydrological needs through sustainable wetland use. Nat Resour Forum 27:117129. https://doi.org/10.1111/1477-8947.00047

Dronova I (2015) Object-based image analysis in wetland research: a review. Remote Sens 7:6380-6413. https://doi.org/10.3390/ rs 70506380

Dronova I, Gong P, Wang L, Zhong L (2015) Mapping dynamic cover types in a large seasonally flooded wetland using extended principal component analysis and object-based classification. Remote Sens Environ 158:193-206. https://doi.org/10.1016/j.rse.2014.10.027

Drusch M, Del Bello U, Carlier S et al (2012) Sentinel-2: ESA's optical high-resolution mission for GMES operational services. Remote Sens Environ 120:25-36. https://doi.org/10.1016/j.rse.2011.11.026

Erb K-H, Haberl H, Jepsen MR et al (2013) A conceptual framework for analysing and measuring land-use intensity. Curr Opin Environ Sustain 5:464-470. https://doi.org/10.1016/j.cosust.2013.07.010

European Space Agency (ESA) (2019) Sentinel High Level Operations Plan (HLOP), v.3, COPE-S1OP-EOPG-PL-15-0020. https:// dragon3.esa.int/documents/247904/685154/Sentinel_High_Level Operations_Plan. Accessed 18 Dec 2020

Farr TG, Rosen PA, Caro E et al (2007) The shuttle radar topography mission. Rev Geophys 45:RG2004. https://doi.org/10.1029/ 2005RG000183

Fick SE, Hijmans RJ (2017) WorldClim 2: new 1-km spatial resolution climate surfaces for global land areas. Int J Climatol 37:4302-4315. https://doi.org/10.1002/joc.5086

Finlayson CM, Davidson N, Pritchard D et al (2011) The Ramsar convention and ecosystem-based approaches to the wise use and 
sustainable development of wetlands. J Int Wildl Law Policy 14: 176-198. https://doi.org/10.1080/13880292.2011.626704

Fitoka E, Tompoulidou M, Hatziiordanou L et al (2020) Water-related ecosystems' mapping and assessment based on remote sensing techniques and geospatial analysis: The SWOS national service case of the Greek Ramsar sites and their catchments. Remote Sens Environ 245:1-12. https://doi.org/10.1016/j.rse.2020.111795

Fluet-Chouinard E, Lehner B, Rebelo L-M et al (2015) Development of a global inundation map at high spatial resolution from topographic downscaling of coarse-scale remote sensing data. Remote Sens Environ 158:348-361. https://doi.org/10.1016/j.rse.2014.10.015

Food and Agriculture Organization (FAO) (2013) GLCN Global Land Cover Network-Africover. FAO, Rome

Franke J, Keuck V, Siegert F (2012) Assessment of grassland use intensity by remote sensing to support conservation schemes. J Nat Conserv 20:125-134. https://doi.org/10.1016/j.jnc.2012.02.001

Gallant JC, Dowling TI (2003) A multiresolution index of valley bottom flatness for mapping depositional areas. Water Resour Res 39. https://doi.org/10.1029/2002WR001426

Gao B (1996) NDWI-A normalized difference water index for remote sensing of vegetation liquid water from space. Remote Sens Environ 58:257-266. https://doi.org/10.1016/S0034-4257(96)00067-3

Gorelick N, Hancher M, Dixon M et al (2017) Google Earth Engine: Planetary-scale geospatial analysis for everyone. Remote Sens Environ 202:18-27. https://doi.org/10.1016/j.rse.2017.06.031

Government of Rwanda (GoR) (2020) Rwanda updated nationally determined contribution. Government of Rwanda (GoR), Kigali, Rwanda

Grohmann CH (2018) Evaluation of TanDEM-X DEMs on selected Brazilian sites: Comparison with SRTM, ASTER GDEM and ALOS AW3D30. Remote Sens Environ 212:121-133. https://doi. org/10.1016/j.rse.2018.04.043

Guo M, Li J, Sheng C et al (2017) A review of wetland remote sensing. Sensors 17:777. https://doi.org/10.3390/s17040777

Heermans J, Ikirezi M (2015) Wetland policies in Rwanda: balancing sustainable use and protection through policy. United States Agency for International Development (USAID), Rwanda

Hess LL, Melack JM, Affonso AG et al (2015) Wetlands of the Lowland Amazon basin: extent, vegetative cover, and dual-season inundated area as mapped with JERS-1 synthetic aperture radar. Wetlands 35: 745-756. https://doi.org/10.1007/s13157-015-0666-y

Hird J, DeLancey E, McDermid G, Kariyeva J (2017) Google earth engine, open-access satellite data, and machine learning in support of large-area probabilistic wetland mapping. Remote Sens 9:1315. https://doi.org/10.3390/rs9121315

Huang W, DeVries B, Huang C et al (2018) Automated extraction of surface water extent from sentinel-1 data. Remote Sens 10:1-18. https://doi.org/10.3390/rs10050797

Jet Propulsion Laboratory (JPL) (2014) U.S. releases enhanced shuttle land elevation data. https://www.jpl.nasa.gov/news/us-releasesenhanced-shuttle-land-elevation-data. Accessed 2 Mar 2021

Junk WJ, An S, Finlayson CM et al (2013) Current state of knowledge regarding the world's wetlands and their future under global climate change: a synthesis. Aquat Sci 75:151-167. https://doi.org/10.1007/ s00027-012-0278-Z

Kasischke ES, Melack JM, Craig Dobson M (1997) The use of imaging radars for ecological applications - A review. Remote Sens Environ 59:141-156. https://doi.org/10.1016/S0034-4257(96)00148-4

Keddy PA, Fraser LH, Solomeshch AI et al (2009) Wet and wonderful: the world's largest wetlands are conservation priorities. Bioscience 59:39-51. https://doi.org/10.1525/bio.2009.59.1.8

Klein I, Gessner U, Dietz AJ, Kuenzer C (2017) Global WaterPack - A $250 \mathrm{~m}$ resolution dataset revealing the daily dynamics of global inland water bodies. Remote Sens Environ 198:345-362. https:// doi.org/10.1016/j.rse.2017.06.045

Kotze DC, Ellery WN, Macfarlane DM, Jewitt GPW (2012) A rapid assessment method for coupling anthropogenic stressors and wetland ecological condition. Ecol Ind 13:284-293. https://doi. org/10.1016/j.ecolind.2011.06.023

Krieger G, Moreira A, Fiedler H et al (2007) TanDEM-X: a satellite formation for high-resolution SAR interferometry. IEEE Trans Geosci Remote Sens 45:3317-3341. https://doi.org/10.1109/ TGRS.2007.900693

Langan C, Farmer J, Rivington M, Smith JU (2018) Tropical wetland ecosystem service assessments in East Africa; A review of approaches and challenges. Environ Model Softw 102:260-273. https://doi.org/10.1016/j.envsoft.2018.01.022

Leemhuis C, Thonfeld F, Näschen K et al (2017) Sustainability in the foodwater-ecosystem nexus: the role of land use and land cover change for water resources and ecosystems in the Kilombero Wetland, Tanzania. Sustainability 9:1513. https://doi.org/10.3390/su9091513

Lehner B, Döll P (2004) Development and validation of a global database of lakes, reservoirs and wetlands. J Hydrol 296:1-22. https://doi.org/ 10.1016/j.jhydrol.2004.03.028

Lehner B, Verdin K, Jarvis A (2008) New global hydrography derived from spaceborne elevation data. Eos Trans AGU 89:93. https://doi. org/10.1029/2008EO100001

Lesiv M, Fritz S, McCallum I et al (2017) Evaluation of ESA CCI prototype land cover map at 20m. https://doi.org/10.13140/RG.2.2.12135.34728

Ludwig C, Walli A, Schleicher C et al (2019) A highly automated algorithm for wetland detection using multi-temporal optical satellite data. Remote Sens Environ 224:333-351. https://doi.org/10.1016/ j.rse.2019.01.017

MacKay H, Finlayson CM, Fernández-Prieto D et al (2009) The role of Earth Observation (EO) technologies in supporting implementation of the Ramsar Convention on Wetlands. J Environ Manage 90: 2234-2242. https://doi.org/10.1016/j.jenvman.2008.01.019

Mahdavi S, Salehi B, Granger J et al (2018) Remote sensing for wetland classification: a comprehensive review. GIScience Remote Sens 55: 623-658. https://doi.org/10.1080/15481603.2017.1419602

Malesu MM, Oduor AR, Chrogony K et al (2010) Rwanda irrigation master plan. Rwanda Ministry of Agriculture and Animal Resources (MINAGRI), Ebony Enterprises Ltd. The World Agroforestry Centre (ICRAF), Nairobi

Markert KN, Markert AM, Mayer T et al (2020) Comparing sentinel-1 surface water mapping algorithms and radiometric terrain correction processing in Southeast Asia utilizing Google earth engine. Remote Sens 12:2469. https://doi.org/10.3390/rs 12152469

Martone M, Bräutigam B, Rizzoli P et al (2012) Coherence evaluation of TanDEM-X interferometric data. ISPRS J Photogramm Remote Sens 73:21-29. https://doi.org/10.1016/j.isprsjprs.2012.06.006

Matthews GVT (2013) The Ramsar Convention on Wetlands: its History and Development by G. V. T. Matthews (Ramsar, 1993). The Ramsar Convention Bureau, Gland

Merot P, Hubert-Moy L, Gascuel-Odoux C et al (2006) A method for improving the management of controversial wetland. Environ Manag 37:258-270. https://doi.org/10.1007/s00267-004-0391-4

Meschy L (1989) La colline et le marais. La gestion des bassins versants au Burundi et au Rwanda. Rural 115:129-151. https://doi.org/10. 3406/rural.1989.3258

Millennium Ecosystem Assessment (Program) (ed) (2005) Ecosystems and human well-being: wetlands and water synthesis: a report of the Millennium Ecosystem Assessment. World Resources Institute, Washington, DC

Mitchell SA (2013) The status of wetlands, threats and the predicted effect of global climate change: the situation in Sub-Saharan Africa. Aquat Sci 75:95-112. https://doi.org/10.1007/s00027-012-0259-2

Muhire I, Ahmed F (2015) Spatio-temporal trend analysis of precipitation data over Rwanda. S Afr Geogr J 97:50-68. https://doi.org/10.1080/ 03736245.2014.924869

Nabahungu NL, Visser SM (2011) Contribution of wetland agriculture to farmers' livelihood in Rwanda. Ecol Econ 71:4-12. https://doi.org/ 10.1016/j.ecolecon.2011.07.028 
Namaalwa S, Van dam AA, Funk A et al (2013) A characterization of the drivers, pressures, ecosystem functions and services of Namatala wetland, Uganda. Environ Sci Policy 34:44-57. https://doi.org/10. 1016/j.envsci.2013.01.002

Ndayisaba F, Nahayo L, Guo H et al (2017) Mapping and Monitoring the Akagera wetland in Rwanda. Sustainability 9:174. https://doi.org/ 10.3390/su9020174

Otsu N (1979) A threshold selection method from gray-level histograms. IEEE Trans Syst Man Cybern 9:62-66. https://doi.org/10.1109/ TSMC.1979.4310076

Ozesmi SL, Bauer ME (2002) Satellite remote sensing of wetlands. Wetl Ecol Manag 10:381-402

Pekel J-F, Cottam A, Gorelick N, Belward AS (2016) High-resolution mapping of global surface water and its long-term changes. Nature 540:418-422. https://doi.org/10.1038/nature20584

Perennou C, Guelmami A, Paganini M et al (2018) Mapping mediterranean wetlands with remote sensing: a good-looking map is not always a good map. In: Advances in Ecological Research. Elsevier, Amsterdam, pp 243-277

Petrou ZI, Manakos I, Stathaki T (2015) Remote sensing for biodiversity monitoring: a review of methods for biodiversity indicator extraction and assessment of progress towards international targets. Biodivers Conserv 24:2333-2363. https://doi.org/10.1007/s10531-015-0947-z

Pham-Duc B, Prigent C, Aires F (2017) Surface water monitoring within Cambodia and the Vietnamese Mekong delta over a year, with sentinel-1 SAR observations. Water 9:366. https://doi.org/10.3390/ w9060366

Ramsar Convention Secretariat (2000) Designating Ramsar sites: strategic framework and guidelines for the future development of the list of wetlands of international importance. Ramsar Convention Secretariat, Gland

RapidEye AG (2007) RapidEye Image Product Specifications. Brandenburg an der Havel, Germany

Rapinel S, Fabre E, Dufour S, et al (2019) Mapping potential, existing and efficient wetlands using free remote sensing data. J Environ Manag 829-839. https://doi.org/10.1016/j.jenvman.2019.06.098

Rebelo L-M, Finlayson CM, Nagabhatla N (2009) Remote sensing and GIS for wetland inventory, mapping and change analysis. J Environ Manag 90:2144-2153. https://doi.org/10.1016/j.jenvman.2007.06.027

Rebelo L-M, Finlayson CM, Strauch A et al (2011) The use of Earth Observation for wetland inventory, assessment and monitoring: An information source for the Ramsar Convention on Wetlands. Springer, Dordrecht

Rizzoli P, Martone M, Gonzalez C et al (2017) Generation and performance assessment of the global TanDEM-X digital elevation model. ISPRS J Photogramm Remote Sens 132:119-139. https://doi.org/ 10.1016/j.isprsjprs.2017.08.008

Rodenburg J, Zwart SJ, Kiepe P et al (2014) Sustainable rice production in African inland valleys: Seizing regional potentials through local approaches. Agric Syst 123:1-11. https://doi.org/10.1016/j.agsy. 2013.09.004

Rwanda Environment Management Agency (REMA) (2008) Etablissement d'un inventaire national rapide des marais et élaboration de 5 avant-projets d'arrêtés ministériels relatifs aux marais. Government of Rwanda (GoR), Kigali, Rwanda

Rwanda Environment Management Agency (REMA) (2009) Rwanda state of environment and outlook report. Rwanda Environment Management Authority (REMA), Kigali, Rwanda

Rwanda Ministry of Agriculture and Animal Resources (MINAGRI) (2011) National rice development strategy (2011-2018). Republic of Rwanda. Ministry of Agriculture and Animal Resources, Kigali, Rwanda
Semeniuk CA, Semeniuk V (1995) A geomorphic approach to global classification for inland wetlands. Vegetatio 118:103-124

Strauch A, Geller G, Grobicki A et al (2016) Towards a global Wetland Observation System: The GEO-Wetlands Initiative. Prague, Czech Republic, pp 1-7

Suwandana E, Kawamura K, Sakuno Y et al (2012) Evaluation of ASTER GDEM2 in comparison with GDEM1, SRTM DEM and Topographic-Map-Derived DEM using inundation area analysis and RTK-dGPS data. Remote Sens 4:2419-2431. https://doi.org/10. 3390/rs4082419

Tachikawa T, Kaku M, Iwasaki A et al (2011) ASTER Global digital elevation model version 2 - summary of validation results. ASTER GDEM Validation Team

Tucker CJ (1979) Red and photographic infrared linear combinations for monitoring vegetation. Remote Sens Environ 8:127-150

United Nations, Department of Economic and Social Affairs, Population Division (2019) World Population Prospects 2019 - Volume II: Demographic Profiles (ST/ESA/SER.A/427). UN, New York

Urai M, Tachikawa T, Fujisada H (2012) Data acquisition strategies for ASTER Global DEM generation. ISPRS Ann Photogramm Remote Sens Spatial Inf Sci I-4:199-202. https://doi.org/10.5194/ isprsannals-I-4-199-2012

van Ittersum MK, van Bussel LGJ, Wolf J et al (2016) Can sub-Saharan Africa feed itself? Proc Natl Acad Sci USA 113:14964-14969. https://doi.org/10.1073/pnas.1610359113

van Oort PAJ, Saito K, Tanaka A et al (2015) Assessment of rice selfsufficiency in 2025 in eight African countries. Glob Food Sec 5:3949. https://doi.org/10.1016/j.gfs.2015.01.002

von der Heyden CJ, New MG (2003) The role of a dambo in the hydrology of a catchment and the river network downstream. Hydrol Earth Syst Sci 7:339-357. https://doi.org/10.5194/hess-7-339-2003

von Grebmer K, Bernstein J, Alders R et al (2020) 2020 global hunger index: one decade to zero hunger - linking health and sustainable food systems. Welthungerhilfe, Concern Worldwide, Bonn

Weise K, Höfer R, Franke J et al (2020) Wetland extent tools for SDG 6.6.1 reporting from the Satellite-based Wetland Observation Service (SWOS). Remote Sens Environ 247:111892. https://doi. org/10.1016/j.rse.2020.111892

Wessel B, Huber M, Wohlfart C et al (2018) Accuracy assessment of the global TanDEM-X Digital Elevation Model with GPS data. ISPRS J Photogramm Remote Sens 139:171-182. https://doi.org/10.1016/j. isprsjprs.2018.02.017

Wood A, Dixon A, McCartney M (2013) People-centred wetland management. In: Wood A, Dixon A, McCartney M (eds) Wetland Management and Sustainable Livelihoods in Africa. Taylor and Francis, United States, pp 1-42

Wood AP, Thawe P (2013) Catchment and wetlands: a functional landscape approach to sustainable use of seasonal wetlands in central Malawi. In: Wood AP, Dixon AB, McCartney M (eds) Wetland Management and Sustainable Livelihoods in Africa. Routledge, Abingdon, pp 63-84

World Agroforestry Centre (ICRAF) (2015) Rwanda Agro Climatic Zones. http://landscapeportal.org/layers/geonode:acz geo. Accessed 10.11.2020

Publisher's Note Springer Nature remains neutral with regard to jurisdictional claims in published maps and institutional affiliations. 